\title{
Reassessing Conceptual Models of ENSO
}

\author{
FELICITY S. GRAHAM \\ Institute for Marine and Antarctic Studies, University of Tasmania, Hobart, Tasmania, Australia \\ JACLYN N. BROWN \\ Oceans and Atmosphere, CSIRO, Hobart, Tasmania, Australia
}

ANDREW T. WITTENBERG

National Oceanic and Atmospheric Administration/Geophysical Fluid Dynamics Laboratory, Princeton, New Jersey

NeIL J. HOLBROOK

Centre of Excellence for Climate System Science, Australian Research Council, and Institute for Marine and Antarctic Studies, University of Tasmania, Hobart, Tasmania, Australia

(Manuscript received 4 November 2014, in final form 13 July 2015)

\begin{abstract}
The complex nature of the El Niño-Southern Oscillation (ENSO) is often simplified through the use of conceptual models, each of which offers a different perspective on the ocean-atmosphere feedbacks underpinning the ENSO cycle. One theory, the unified oscillator, combines a variety of conceptual frameworks in the form of a coupled system of delay differential equations. The system produces a self-sustained oscillation on interannual time scales. While the unified oscillator is assumed to provide a more complete conceptual framework of ENSO behaviors than the models it incorporates, its formulation and performance have not been systematically assessed. This paper investigates the accuracy of the unified oscillator through its ability to replicate the ENSO cycle modeled by flux-forced output from the Australian Community Climate and Earth-System Simulator Ocean Model (ACCESS-OM). The anomalous sea surface temperature equation reproduces the main features of the corresponding tendency modeled by ACCESS-OM reasonably well. However, the remaining equations for the thermocline depth anomaly and zonal wind stress anomalies are unable to accurately replicate the corresponding tendencies in ACCESS-OM. Modifications to the unified oscillator, including a diagnostic form of the zonal wind stress anomaly equations, improve its ability to emulate simulated ENSO tendencies. Despite these improvements, the unified oscillator model is less adept than the delayed oscillator model it incorporates in capturing ENSO behavior in ACCESS-OM, bringing into question its usefulness as a unifying ENSO framework.
\end{abstract}

\section{Introduction}

Bjerknes (1969) first recognized that the growth of El Niño-Southern Oscillation (ENSO) events is due to a positive feedback mechanism resulting from oceanatmosphere interactions in the equatorial Pacific. Specifically, during warm ENSO events, an initial positive sea surface temperature (SST) anomaly develops in the

Corresponding author address: Felicity Graham, Institute for Marine and Antarctic Studies, University of Tasmania, Private Bag 129, Hobart, Tasmania 7001, Australia.

E-mail: fsm@utas.edu.au eastern equatorial Pacific, reducing the SST gradient along the equator. As a result, the atmospheric Walker circulation is weakened with weakening equatorial trade winds, leading to surface wind stress changes that reinforce the original SST anomaly-a positive feedback mechanism collectively known as the Bjerknes positive feedback. Since the seminal work of Bjerknes (1969), other important research has been undertaken to identify and describe the feedback mechanisms underpinning the decay and phase change of ENSO events and to test their ability to represent ENSO variability (Barnett 1977). Conceptual models have played a very valuable role in advancing our understanding of ENSO 
feedback mechanisms by their relatively simple representation of often complex dynamics, without replicating the entire ocean-atmosphere coupled system. These conceptual models usually combine the Bjerknes positive feedback mechanism with one or more negative feedback mechanisms, which enables them to produce oscillations on interannual time scales (approximately every 2-7 years; Wang 2001, hereafter W01; Wang and Picaut 2004). The feedback mechanisms of conceptual models are often tested against observations and simulations of coupled general circulation models (CGCMs; Kessler 1991; Picaut et al. 1996; Clarke et al. 2000; Meinen and McPhaden 2000, 2001; Boulanger et al. 2003; Hasegawa and Hanawa 2003; Mechoso et al. 2003; Bettio 2007; Choi et al. 2013).

One of the earliest conceptual models of ENSO, the delayed oscillator, was instrumental in highlighting the importance of equatorial Kelvin and Rossby waves in the transition of an ENSO event (Schopf and Suarez 1988; Suarez and Schopf 1988; Battisti and Hirst 1989). In the delayed oscillator, the growth of an El Niño event is driven by the Bjerknes positive feedback mechanism: westerly wind anomalies in the central Pacific incite an eastward propagating downwelling Kelvin wave that acts to increase SST in the Niño-3 region. At the same time, offequatorial upwelling Rossby waves reflect at the western Pacific boundary as an equatorial upwelling Kelvin wave, which propagates eastward, shoaling the equatorial thermocline and allowing cool, subsurface waters to suppress the warm SST anomaly in the eastern equatorial Pacific. Previous studies (Schneider et al. 1997) demonstrate that wave reflection at the western boundary does indeed play a role in the termination of some ENSO events; however, the damping (negative feedback) due to wave reflection alone is not always sufficient in describing the transition between ENSO events (Li and Clarke 1994; McPhaden and Yu 1999).

Similar to the delayed oscillator, the western Pacific oscillator describes the effect of local wind-induced wave dynamics in the growth and termination of an ENSO event (Weisberg and Wang 1997). During an El Niño event, an increase in off-equatorial sea level pressure in the western Pacific generates local easterly wind anomalies. These wind anomalies force an upwelling, eastward-propagating Kelvin wave that shoals the thermocline in the eastern Pacific, terminating the event. Previous studies have confirmed that locally generated waves in the western Pacific do play a role in the termination of an ENSO event (McPhaden and Yu 1999; McPhaden 2004), most likely operating in concert with other negative feedback mechanisms (Boulanger and Menkes 2001; Boulanger et al. 2003).

The recharge oscillator (Jin 1997a,b) has advanced our understanding of the role of equatorial heat content in ENSO phase change. Under this framework, the termination of an El Niño event is achieved through poleward Sverdrup transport of equatorial heat content incited by changes in the wind stress curl in the central equatorial Pacific (Clarke et al. 2007; Brown and Fedorov 2010). The Sverdrup transport leaves the equatorial $\mathrm{Pa}-$ cific thermocline anomalously shallow, allowing for the transition to a cool event (La Niña). Given the role of wave dynamics in inducing the anomalous thermocline tilt that lead to the discharge/recharge of equatorial heat content, the recharge oscillator can be loosely regarded as an integrated version of the delayed oscillator. The mechanism described by the recharge oscillator is hypothesized to have value in forecasting ENSO beyond the spring persistence barrier because of the slow adjustment time of oceanic equatorial heat content (McPhaden 2003). To leading order, the recharge oscillator agrees well with observations of eastern Pacific (i.e., canonical) El Niño events, with SST anomalies peaking in the cold tongue region (Meinen and McPhaden 2000). However, the recharge oscillator mechanism is less able to emulate observations of central Pacific (or Modoki) events with peak warming near the western Pacific warm pool edge, as the discharge and recharge of equatorial heat content plays a less important role during central Pacific El Niño events (Kug et al. 2010; McPhaden 2012; Singh and Delcroix 2013; Graham et al. 2014). It has also been suggested that external forcing is required to initiate central Pacific El Niño events, and this event can be described as a damped oscillation, rather than the selfsustaining oscillation that describes the eastern Pacific El Niño events (Yeh et al. 2014).

Finally, the advective-reflective oscillator (Picaut et al. 1997) emphasizes the importance of the edge of the western Pacific warm pool in the growth and transition of an ENSO event. Development of a warm event is provided by the Bjerknes positive feedback mechanism and eastward advection of the edge of the warm pool by anomalous zonal currents. The subsequent transition to La Niña occurs because of westward displacement of the edge of the warm pool by two sets of zonal currents. The first set is a result of wave reflection at both boundaries of the Pacific. The second is the mean westward zonal equatorial surface current that is stronger in the eastern Pacific and has a greater influence on the westward advection of the warm pool edge. Brown et al. (2014) have further suggested it is the gradient of the zonal current that is important in setting the decay rate. The advective-reflective oscillator generally accords well with observations, playing an important role in the growth and decay of the 1997-98 El Niño event (Picaut et al. 1996; Boulanger and Menkes 1999). Shu and Clarke (2002) use a similar mechanism to that described 
by the advective-reflective oscillator in an intermediate complexity model to demonstrate that zonal advection and wave dynamics are able to reproduce the patterns of SST anomaly evolution characteristic of central and eastern Pacific ENSO events.

W01 combined the four above-mentioned conceptual models in a system of delay differential equations that became known as the unified oscillator (UO). W01 argues that since it is likely that multiple mechanisms are responsible for the decay of an ENSO event, the unification of a number of conceptual models should more accurately describe the ENSO cycle than each of the mechanisms alone. Using selected parameter values, W01 demonstrates that the UO produces oscillations on ENSO time scales (every 2-7 years). The UO is an often cited theory to account for ENSO growth and transition (e.g., Guilyardi et al. 2003; Wang and Picaut 2004; Guilyardi et al. 2009; Duan et al. 2013; Singh and Delcroix 2013); however, the assumptions underlying the UO and its relevance have not been systematically assessed. Importantly, it has not been established that the UO model is able to simulate a realistic ENSO period when fit to observations or model data.

In this study, we explore the value of the $\mathrm{UO}$ as a conceptual framework for ENSO. We apply the UO theory to the output of an ocean general circulation model (OGCM) simulation-a historical surface fluxforced simulation of the Australian Community Climate and Earth-System Ocean Model (ACCESS-OM) - with the aim of determining the extent to which the UO equations for the SST anomaly, thermocline depth anomaly, and zonal wind stress anomaly tendencies can diagnose their corresponding simulated ENSO tendencies. We investigate whether the UO has greater diagnostic power than the models it combines, comparing these underpinning models with their original formulations.

\section{Data and methods}

\section{a. ACCESS-OM}

Monthly means of the analyzed variables are derived from the output of a historical air-sea flux-forced simulation using the Australian Community Climate and Earth System Simulator Ocean Model (ACCESS-OM; Bi et al. 2013a). ACCESS-OM is the ocean-sea ice component of the ACCESS Coupled Model (ACCESS$\mathrm{CM}$ ), a model participant in the Coupled Model Intercomparison Project phase 5 (CMIP5; Bi et al. 2013b). ACCESS-OM draws its codebase and most of its configuration from the National Oceanic and Atmospheric Administration (NOAA)/Geophysical Fluid Dynamics
Laboratory (GFDL) MOM4 ocean model, versions of which have been used in most of GFDL's contributions to CMIP3 and CMIP5: CM2.0 and CM2.1 (Delworth et al. 2006; Gnanadesikan et al. 2006; Wittenberg et al. 2006), ESM2M (Dunne et al. 2012), CM3 (Griffies et al. 2011), CM2.5 (Delworth et al. 2012), and the ForecastOriented Low Ocean Resolution version CM2.5 (CM2.5-FLOR; Jia et al. 2015; Vecchi et al. 2014). ACCESS-OM has a zonal resolution of $1^{\circ}$ and a meridional resolution of $13^{\circ}$ between $10^{\circ} \mathrm{S}$ and $10^{\circ} \mathrm{N}$, which extends to $1^{\circ}$ between $10^{\circ} \mathrm{S}\left({ }^{\circ} \mathrm{N}\right)$ and $20^{\circ} \mathrm{S}\left({ }^{\circ} \mathrm{N}\right)$. The vertical discretization uses a $z^{*}$ coordinate scheme (Adcroft and Campin 2004), and there are 50 vertical levels with a resolution extending from $10 \mathrm{~m}$ in the upper $200 \mathrm{~m}$ to approximately $333 \mathrm{~m}$ in the deep ocean. The ACCESS-OM simulation analyzed here is forced with the surface heat, freshwater, and momentum fluxes derived from the Large and Yeager (2009) forcing and bulk formulae. The simulation follows the protocols of the CLIVAR Working Group on Ocean Model Development interannually varying Coordinated Ocean-Ice Reference Experiments version 2 (CORE-II; Griffies et al. 2012). The accuracy of the CORE-II forcing in the tropical Pacific is difficult to verify because of a sparsity of observational data; however, the incoming solar radiation is generally accurate to within $10 \mathrm{Wm}^{-2}$ of mooring data (Large and Yeager 2009).

Anomalies are calculated by subtracting the annual cycle from the monthly mean values of the model outputs. Multivariate empirical orthogonal functions (EOFs) are then applied to the SST, thermocline depth, and zonal wind stress anomalies in the UO, to analyze their spatial patterns of variability and determine the optimal averaging regions from the ACCESS-OM simulation that correspond to the regions defined in W01 (Fig. 1). The region of maximum SST anomaly variability in the eastern Pacific is within the bounds of the standard Niño-3 region $\left(5^{\circ} \mathrm{S}-5^{\circ} \mathrm{N}, 150^{\circ}-90^{\circ} \mathrm{W}\right)$; zonal wind stress anomalies are averaged in the modified Niño-4 region $\left(5^{\circ} \mathrm{S}-5^{\circ} \mathrm{N}, 150^{\circ} \mathrm{E}-160^{\circ} \mathrm{W}\right)$, which is located $10^{\circ}$ west of the standard region, and in the Niño- 5 region $\left(5^{\circ} \mathrm{S}-5^{\circ} \mathrm{N}, 120^{\circ}-140^{\circ} \mathrm{E}\right)$; and thermocline depth anomalies are averaged in the modified Niño- 6 region $\left(8^{\circ}-\right.$ $\left.16^{\circ} \mathrm{N}, 150^{\circ}-170^{\circ} \mathrm{E}\right)$. While the modified Niño- 6 region is relatively small, it represents a region of maximum interannual variability in thermocline depth and, as such, suffices to take account of the behavior of, and variability in, thermocline depth anomalies during ENSO events. In what follows, we refer to the modified regions as Niño-4* and Niño-6*, to avoid confusion with the standard versions. The depth-averaged potential temperature above $300 \mathrm{~m}$ is used as a proxy for the thermocline depth, as it is strongly correlated with the $20^{\circ} \mathrm{C}$ 


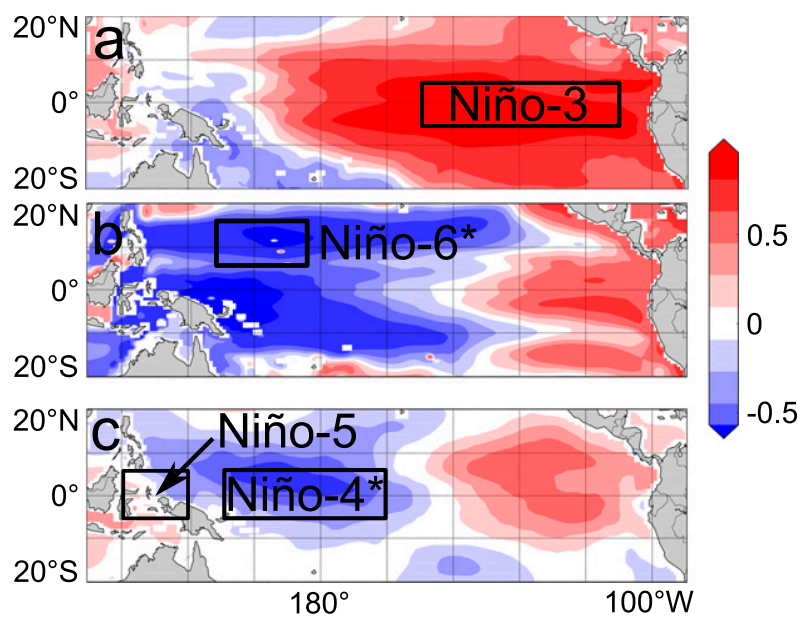

FIG. 1. Averaging regions for the unified oscillator determined from EOF analysis of (a) SST anomalies, (b) thermocline depth anomalies, and (c) zonal wind stress anomalies. The units are normalized between -1 and 1 and the contour intervals are 0.2 units, with values between -0.2 and 0.2 in white.

isotherm depth. That is, for variables averaged in the Niño- $6^{*}$ region, $89 \%$ of the variance in the $20^{\circ} \mathrm{C}$ isotherm depth anomaly is explained by the depth-averaged temperature anomaly above $300 \mathrm{~m}$, for an estimated regression coefficient of $20 \mathrm{~m}^{\circ} \mathrm{C}^{-1}$.

\section{b. The simulated tropical Pacific}

In general, ACCESS-OM is a realistic model that reproduces historical ENSO-like variability well (Bi et al. 2013a; Graham et al.2014), although its accuracy is uncertain to a degree since the atmospheric fluxes forcing ACCESS-OM are poorly known (Wittenberg 2004). One limit of this study is the relatively short period of time-60 years from 1948 to 2007-over which this ACCESS-OM simulation extends. An alternative would be to use a simulation from a CGCM, although this would have introduced model biases, further complicating the interpretation of our results (Brown et al. 2013).

Surface and subsurface potential temperature data from the Australian Bureau of Meteorology Research Centre (BMRC) ocean analyses (Smith 1995), derived predominantly from the Tropical Atmosphere Ocean/ Triangle Trans-Ocean Buoy Network mooring data and ship-of-opportunity XBT data, are compared with the corresponding ACCESS-OM data. The spatial pattern of SST is similar between the two datasets, although ACCESS-OM is generally warmer in the far eastern offequatorial Pacific and cooler in the central-eastern equatorial Pacific (Figs. 2a-c). Along the equator, ACCESS-OM produces a realistic pattern of subsurface potential temperature, with a deep warm pool in the western equatorial Pacific, shoaling to a thin mixed layer in the eastern equatorial Pacific (Figs. 2d-f). ACCESS$\mathrm{OM}$ is slightly less thermally stratified near the surface. The mean equatorial thermocline depth in ACCESSOM compares well with the BMRC data, although it has a slightly steeper east-west slope in the centraleastern Pacific $\left(150^{\circ}-120^{\circ} \mathrm{W}\right)$.

Figure 3 shows the bias in the seasonal mean SST from the ACCESS-OM simulation. In all seasons, the western Pacific warm pool is warmer in the far west $\left(120^{\circ}-140^{\circ} \mathrm{E}\right)$ in ACCESS-OM than in the BMRC data, and the equatorial SST in the central-eastern equatorial Pacific $\left(150^{\circ}-100^{\circ} \mathrm{W}\right)$ is notably cooler in ACCESS-OM during austral winter and spring.

The unfiltered Niño-3 time series $\left(5^{\circ} \mathrm{S}-5^{\circ} \mathrm{N}, 150^{\circ}-\right.$ $90^{\circ} \mathrm{W}$ ) derived from the ACCESS-OM simulation is
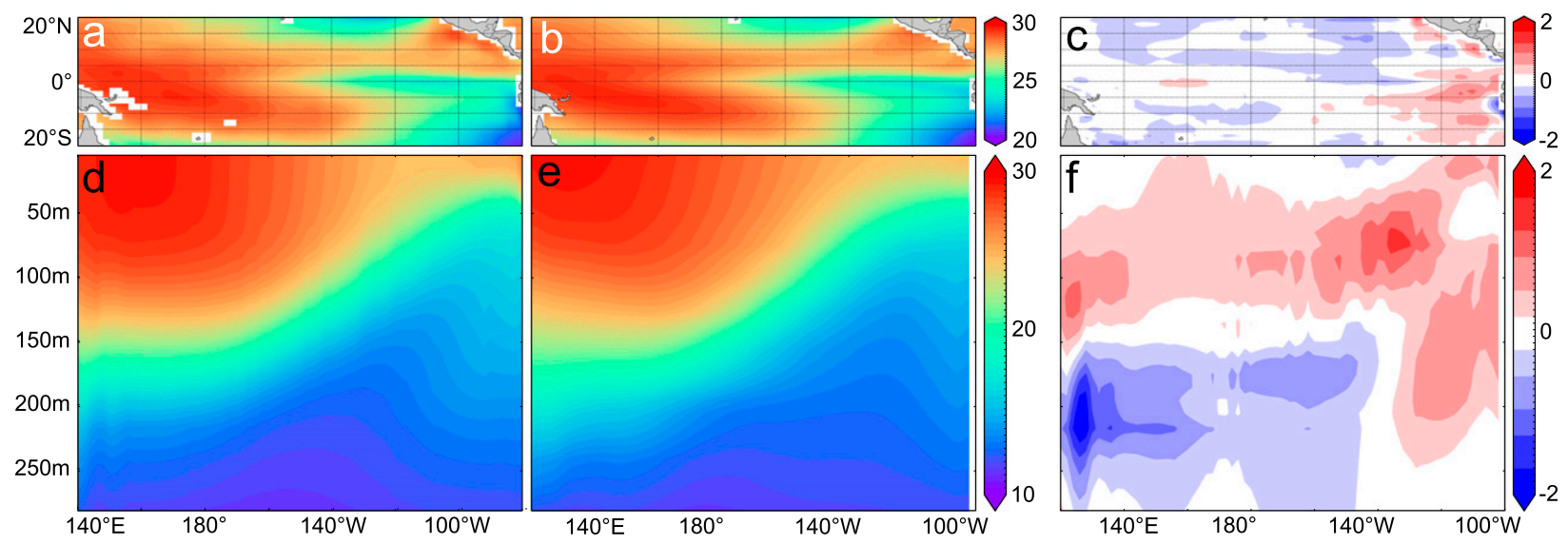

FIG. 2. Comparison between (top) mean surface and (bottom) mean equatorial subsurface potential temperature data derived from the (a),(d) BMRC dataset and (b),(e) the ACCESS-OM simulation (Graham et al. 2014). (c),(f) The difference between the ACCESS-OM and BMRC data is also shown. Data are in units of ${ }^{\circ} \mathrm{C}$. Both the ACCESS-OM data and the BMRC data are averaged over the period 1980-2004. 

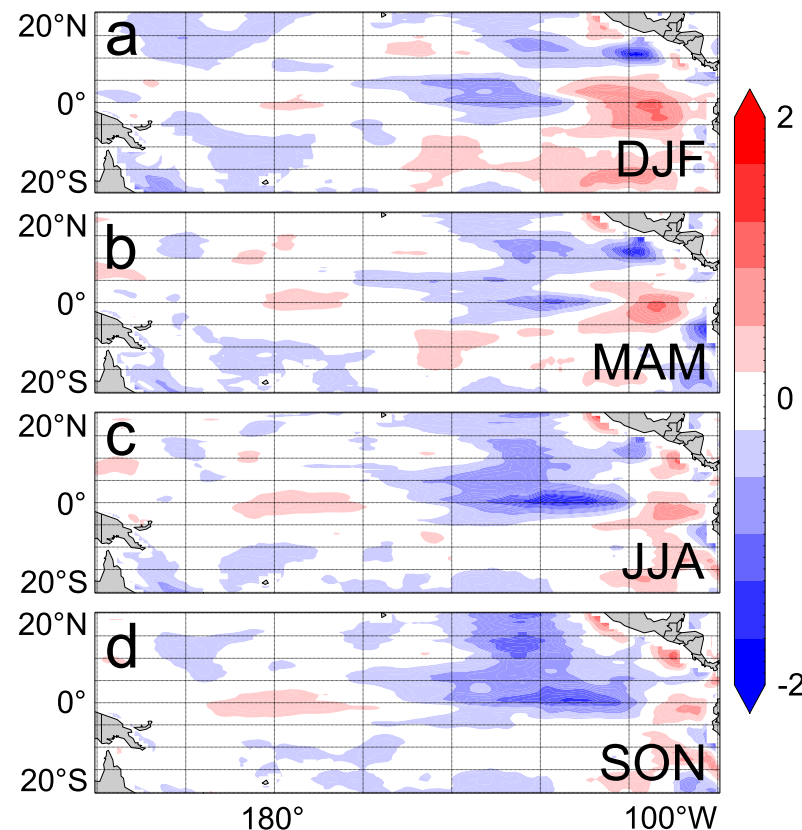

FIG. 3. Difference between seasonal mean sea surface temperature $\left({ }^{\circ} \mathrm{C}\right)$ derived from the ACCESS-OM simulation and the BMRC dataset (Graham et al. 2014). The contour intervals are $0.4^{\circ} \mathrm{C}$ (data with values between $-0.2^{\circ}$ and $0.2^{\circ} \mathrm{C}$ are in white)

compared with the corresponding unfiltered time series derived from the BMRC dataset, the Simple Ocean Data Assimilation (SODA) version 2.2.4 (Carton and Giese 2008), and the NOAA Extended Reconstructed SST (ERSST) version 3 dataset (provided by the NOAA/ESRL from their website at http://www.esrl. noaa.gov/psd/; Fig. 4a). The magnitude and phase of ENSO is very similar across the four datasets, although the magnitude of ENSO events in ACCESS-OM tends to be slightly larger than the other products. Figure $4 \mathrm{~b}$ compares the standard deviation of the SST anomaly at each longitude and averaged between $2^{\circ} \mathrm{S}$ and $2^{\circ} \mathrm{N}$ for the ACCESS-OM, BMRC, SODA, and ERSST datasets. For the same range of years (1980-2000), the ERSST data have a large spike in standard deviation near $100^{\circ} \mathrm{W}$, while the remaining datasets display similar variability along the equator. Figures $4 \mathrm{c}-\mathrm{e}$ illustrate the unfiltered time series of Niño-3 thermocline depth anomalies, Niño-4* zonal wind stress anomalies, and Niño-5 zonal wind stress anomalies, respectively, from the ACCESS-OM and SODA simulations. There is generally a high level of agreement between ACCESSOM and SODA. Prior to 1970, the Niño-5 zonal wind stress anomalies in ACCESS-OM have a positive bias compared with those of SODA. However, as mentioned previously, the atmospheric fluxes forcing both ACCESS$\mathrm{OM}$ and SODA, including the zonal wind stresses, are poorly known, such that the significance of differences between the Niño-4* and Niño-5 zonal wind stress anomalies in ACCESS-OM and SODA is difficult to accurately quantify.

Mean surface zonal currents from the Ocean Surface Current Analysis Real-Time (OSCAR) and ACCESSOM datasets are plotted in Fig. 5. The ACCESS-OM data display a small $\left(<0.2 \mathrm{~m} \mathrm{~s}^{-1}\right)$ westward bias in the eastern equatorial Pacific $\left(5^{\circ} \mathrm{S}-5^{\circ} \mathrm{N}, 130^{\circ}-80^{\circ} \mathrm{W}\right)$ and in the western-central Pacific $\left(2^{\circ}-8^{\circ} \mathrm{N}, 130^{\circ} \mathrm{E}-130^{\circ} \mathrm{W}\right)$, and an eastward bias $\left(<0.5 \mathrm{~m} \mathrm{~s}^{-1}\right)$ across the entire basin at approximately $10^{\circ} \mathrm{N}$ and at the equator between $160^{\circ} \mathrm{E}-140^{\circ} \mathrm{W}$. Both the ACCESS-OM and OSCAR data are averaged over the period 1993-2007 and in the top $30 \mathrm{~m}$.

\section{c. Generalized least squares regression}

To investigate the relative importance of the feedback mechanisms described in the UO and its underpinning conceptual models, parameter values are obtained by fitting the relevant model equations to the corresponding tendencies calculated directly from the ACCESSOM simulation data (using centered differences). That is, we fit the UO and underpinning conceptual model formulations of the following equation

$$
\frac{d Y}{d t}=\alpha_{1} X_{1}+\alpha_{2} X_{2}+\cdots+\alpha_{n} X_{n}+E_{t},
$$

where $d Y / d t$ is the tendency obtained directly from the ACCESS-OM simulation data and $\left\{X_{n}\right\}$ are the independent variables, to find estimates of the coefficients $\left\{\alpha_{n}\right\}$ that minimize the error term $E_{t}$. However, as is often the case for climate data, we find that our data are serially correlated. It follows that ordinary least squares (OLS) regression of each of the model equations will not necessarily permit robust estimates of the standard errors and $t$ statistics of the fit, as evidenced in the autocorrelation (ACF) and partial autocorrelation (PACF) functions of the fitted residuals (von Storch and Zwiers 1999). For example, the ACF and PACF estimates for the OLS fit of the delayed oscillator SST anomaly tendency Eq. (8) clearly demonstrate serial correlation in the residuals (Fig. 6a).

To address the issue of serial correlation, we refit the conceptual model equations assuming a correlated error structure using generalized least squares (GLS) regression. We follow a similar procedure to that presented in Dong et al. (2008). Autoregressive processes of order $p$ [AR( $p)$; von Storch and Zwiers 1999], for values of $p=0,1,2$, and 3 , are fit to the residuals to remove the correlation structure of the errors (e.g., Fig. 6b). Since the models AR(0), AR(1), .., AR(3) are nested, the optimal values of $p$ can be easily determined from a 

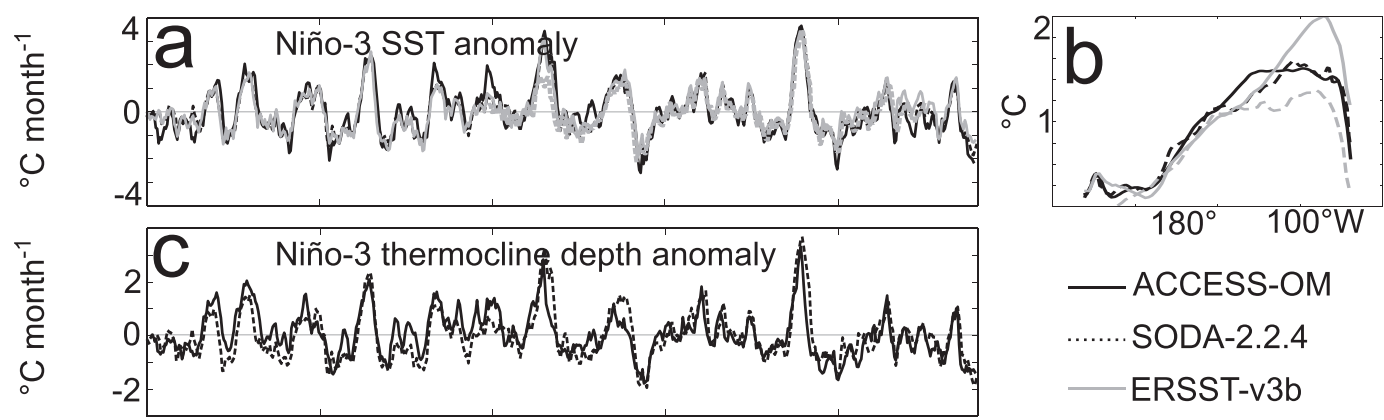

- ACCESS-OM

........SODA-2.2.4

-ERSST-v3b

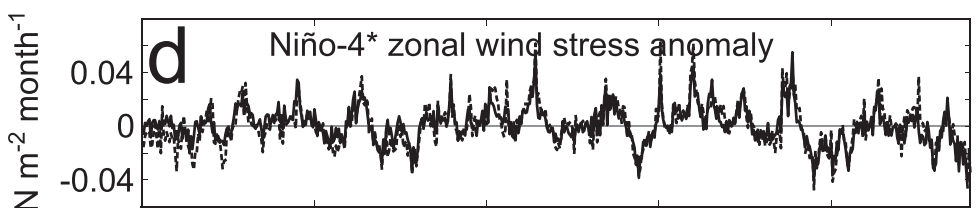

-..... BMRC

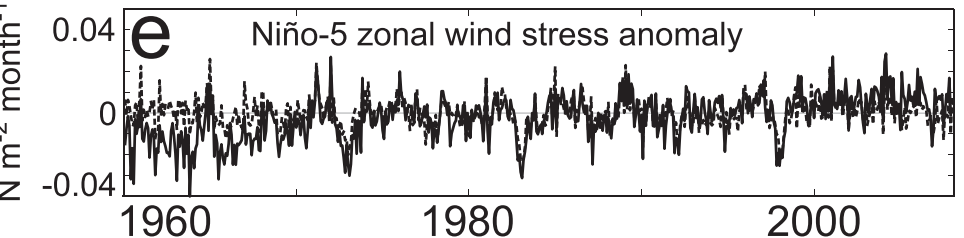

FIG. 4. Unfiltered data derived from the ACCESS-OM simulation are illustrated by the black solid lines, data from SODA v2.2.4 are illustrated by the dotted lines, data derived from ERSST v3b are illustrated by the gray solid lines, and data derived from the BMRC dataset are illustrated by the gray dashed lines for (a) Niño- $3\left(5^{\circ} \mathrm{S}-5^{\circ} \mathrm{N}, 150^{\circ}-90^{\circ} \mathrm{W}\right)$ SST anomaly indices, (b) standard deviation over the period $1980-2000$ of the SST anomalies averaged over $2^{\circ} \mathrm{S}-2^{\circ} \mathrm{N}$ at each longitude, (c) Niño-3 thermocline depth anomaly indices, (d) Niño- $4^{*}\left(5^{\circ} \mathrm{S}-5^{\circ} \mathrm{N}, 150^{\circ} \mathrm{E}-160^{\circ} \mathrm{W}\right)$ zonal wind stress anomaly indices, and (e) Niño- $5\left(5^{\circ} \mathrm{S}-5^{\circ} \mathrm{N}, 120^{\circ}-140^{\circ} \mathrm{E}\right)$ zonal wind stress anomaly indices.

likelihood ratio test. In each fitting, the $\mathrm{ACF}$ and $\mathrm{PACF}$ estimates are used to verify that 1$)$ the time series are serially correlated and 2) the $\operatorname{AR}(p)$ model selected using the likelihood ratio test indeed minimizes the residuals from which the effect of the fitted correlation structure has been removed. GLS analysis is undertaken using the open-source $\mathrm{R}$ statistical programming language (http://www.r-project.org/; R Development Core Team 2008). The regression model is also tested using a $K$-fold cross-validation scheme (Hastie et al. 2001; Lima et al. 2009). The data are divided into $K=9$ equal samples, which ensures that the resulting sequence of approximately 60 months consists of at least one temporal degree of freedom for the ENSO system. The data are iterated $K-1$ times: on each iteration, parameters from the conceptual model equations are estimated using the first $k=1,2, \ldots, K-1$ samples of withheld data. The skill of the model is then tested by comparing the curve calculated using the fitted values from the $k$ samples with the predicted value (the tendency) from the $k+1$ th sample. On each iteration nonzero delay parameters are chosen to minimize the root-meansquare error (rmse) of the cross-validated results, while yielding nonnegative values for the coefficients (the condition $\eta>\mu>\delta$ is also applied). The final rmse is the average of each of the $K-1$ iterations. The anomalous data are linearly detrended and filtered prior to fitting using a 12-month Parzen filter to remove variability with frequencies shorter than 12 months. We

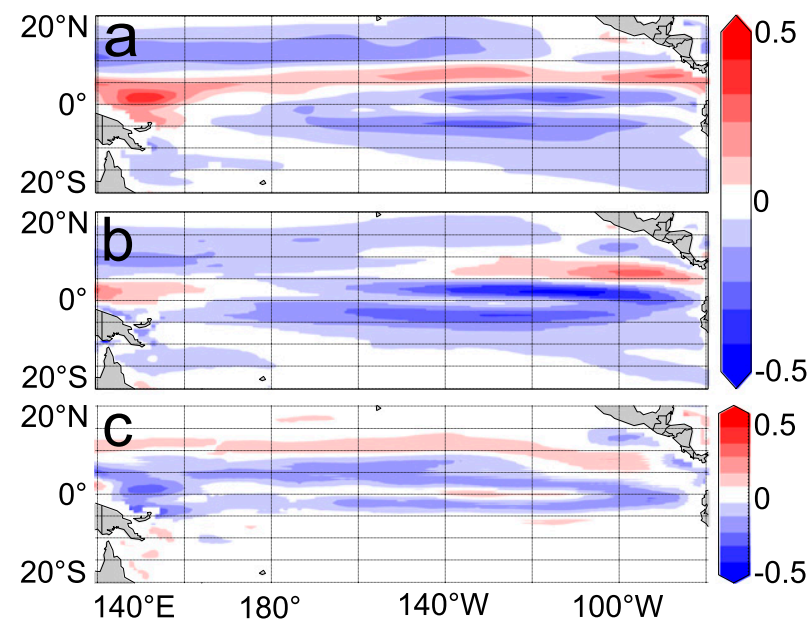

FIG. 5. Comparison between mean surface zonal current data $\left(\mathrm{m} \mathrm{s}^{-1}\right)$ derived from (a) OSCAR and (b) ACCESS-OM (Graham et al. 2014) and (c) the difference between the ACCESS-OM and OSCAR data. The data are averaged over the period 1993-2007 in the top $30 \mathrm{~m}$. The contour intervals are $0.1 \mathrm{~m} \mathrm{~s}^{-1}$. 
a
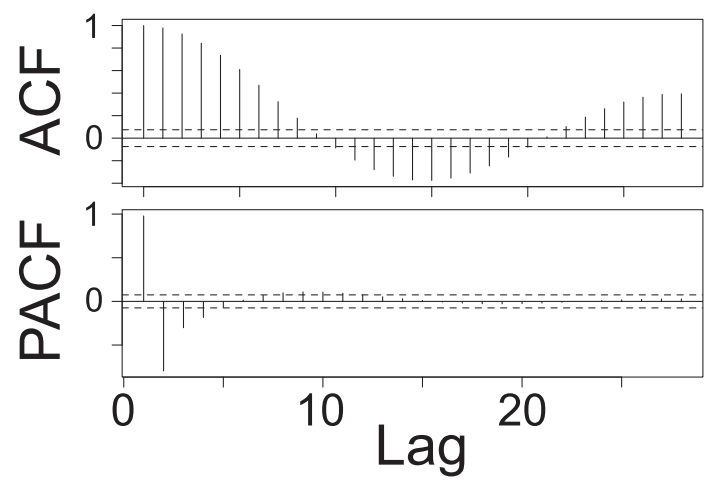

b
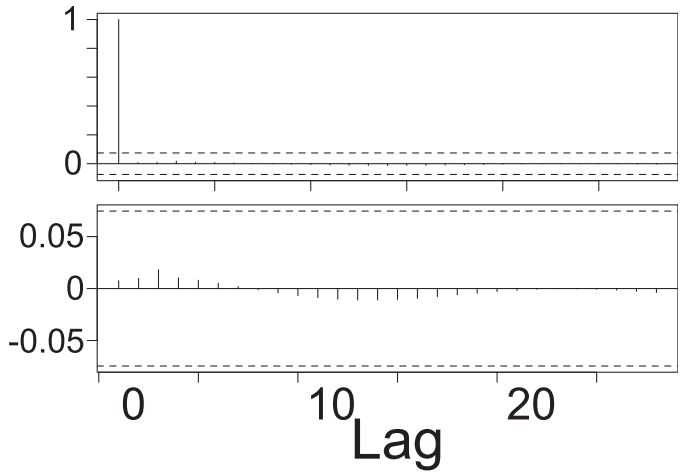

FIG. 6. (top) ACF and (bottom) PACF functions of the residuals from the fitting analysis of the original delayed oscillator SST anomaly Eq. (8). (a) The results from ordinary least squares, where no error correlation structure is assumed, and (b) the minimization of the residuals when an $\mathrm{AR}(3)$ error correlation structure is assumed. The dashed lines represent the $95 \%$ confidence intervals for the null hypothesis that the autocorrelation and partial autocorrelation values are zero for lags of one or more. Note the different scales on the $y$ axes of the PACFs in (a) and (b).

choose a 12-month Parzen filter to remove variability on time scales of 12 months or shorter for three key reasons:

1) We investigate the ability of the UO and its underpinning conceptual models to represent ENSO variability, representing time scales of $2-7 \mathrm{yr}$. Including variability with frequencies higher than 12 months obscures the slower ENSO adjustment time scales that are sought to be modeled by the UO.

2) Our 12-month Parzen filter is a conservative filtering technique compared with similar studies to the one undertaken here (e.g., Mechoso et al. 2003). Indeed, Mechoso et al. (2003) fit the recharge oscillator and delayed oscillator conceptual models to the ENSO cycle-that is, a time series representing $2-7-y r$ frequencies, where higher and lower frequency variability had first been extracted.

3) By repeating the analysis using a 3-month Parzen filter, we found that the resulting fits of the UO and its underpinning models to the ACCESS-OM data were considerably worse than when a 12-month filter was used. For the UO model, the variance explained by the curve to which a 3-month filter had been applied was only $32 \%$, whereas when a 12 -month filter was used, the explained variance increased to $50 \%$. For the prognostic equations for zonal wind stress averaged in the Niño- $4 *$ and Niño-5 regions, neither the 3-month nor the 12-month Parzen filter resulted in fits that explained more than $1 \%$ of the variance in the tendency terms calculated directly from ACCESS-OM.

\section{The conceptual models}

The UO model equations are first introduced, followed by the delayed oscillator, recharge oscillator, and western Pacific oscillator equations that are derived from the UO. The advective-reflective oscillator equation for the SST anomaly tendency, that includes one extra term than in the corresponding UO equation, describing reflection of waves at the eastern boundary, is also introduced. The UO versions of the delayed oscillator, recharge oscillator, and western Pacific oscillator models are further contrasted with their original formulations.

\section{a. The unified oscillator}

The UO is represented by the following system of delay differential equations (W01):

$$
\begin{aligned}
& \frac{d T_{3}}{d t}=\underbrace{a \tau_{4}^{x}}_{[1]} \underbrace{-b_{1} \tau_{4}^{x}(t-\eta)}_{[2]}+\underbrace{b_{2} \tau_{5}^{x}(t-\delta)}_{[3]}-\underbrace{\varepsilon T_{3}}_{[4]}, \\
& \frac{d h_{6}}{d t}=-c \tau_{4}^{x}(t-\lambda)-R_{h} h_{6}, \\
& \frac{d \tau_{4}^{x}}{d t}=e T_{3}-R_{\tau_{4}^{r} \tau_{4}^{x}} \\
& \frac{d \tau_{5}^{x}}{d t}=k h_{6}-R_{\tau_{5}^{x}} \tau_{5}^{x},
\end{aligned}
$$

where $T_{3}$ is the Niño-3 SST anomaly, derived from the Lamont intermediate-complexity model of equatorial SST (Zebiak and Cane 1987), and $h_{6}$ is the Niño- $6^{*}$ region thermocline depth anomaly, adapted from the vorticity equation for low-frequency, off-equatorial 
Rossby waves (Meyers 1979; Kessler 1990). A reducedgravity atmospheric model forced by thermodynamic heating anomalies is used in W01 to derive the zonal wind stress anomalies, namely, the Niño-4* region averaged zonal wind stress anomaly $\tau_{4}^{x}$ and the Niño-5 region averaged zonal wind stress anomaly $\tau_{5}^{x}$. The derivation of Eqs. (2)-(5) in W01, including the underlying balance relations, is outlined in the appendix. The terms $a, b_{1}, b_{2}, c, e, k, \varepsilon, R_{h}, R_{\tau_{4}^{k}}$, and $R_{\tau_{5}^{r}}$ are constants. In the original paper, W01 uses theoretical arguments and similar studies (e.g., Battisti and Hirst 1989; Weisberg and Wang 1997) to derive values for these coefficients and to constrain the system to ensure an oscillation on ENSO-like time scales. The suitability of the W01 parameter values to the ACCESS-OM simulation is analyzed in section 4.

Term 1 on the right-hand side of Eq. (2) is the Bjerknes positive feedback term, which describes the atmospheric response to changes in SST. Term 2 represents reflection of off-equatorial Rossby waves at the western boundary (i.e., the delayed oscillator), where $\eta$ represents the time taken for the Rossby waves to reflect at the western boundary and propagate as an equatorial Kelvin wave to the eastern Pacific. Term 3 in Eq. (2) represents the forcing stress from easterly anomalous winds in the western Pacific generating an eastward-propagating equatorial Kelvin wave (the western Pacific oscillator), where $\delta$ represents the time taken for the Kelvin wave to propagate eastward. Term 4 in Eq. (2) is a damping term that takes into account processes such as advection and convection, limiting the growth of the ENSO mode. In W01 the damping term is cubic; however, in our fitting analyses we find that a linear damping term produces smaller rmses than a cubic term and is therefore adopted here.

In Eq. (3), the first term on the right-hand side represents the meridional transport of heat content (the recharge oscillator), where the delay parameter $\lambda$ is the lag time between the basinwide discharge-recharge mode and the anomalous zonal wind stress. The second term on the right-hand side of Eq. (3) represents damping from a variety of processes. Equations (4) and (5) close the system by relating zonal wind stress anomalies to SST and thermocline depth anomalies. The derivative form of Eqs. (4) and (5) do not conform to the steady atmosphere used in previous studies (Battisti and Hirst 1989; Jin 1997a,b). Curiously, neither of Eqs. (4) and (5) include explicit noise terms, which contribute significantly to wind stresses in the Niño-4* and Niño-5 regions (Vecchi et al. 2006). We also note that Eq. (5) relates $\tau_{5}^{x}$ directly to thermocline depth anomalies, when in reality $\tau_{5}^{x}$ depends on $h_{6}$ through local SST anomalies, which themselves are a function of the position of the warm pool edge, variations in wind- and buoyancyinduced mixing, and barrier layer transience.

By a series of approximations, the UO reduces to modified formulations of the delayed oscillator (denoted the UDO), recharge oscillator (URO), and western Pacific oscillator (UWPO), which are discussed in the following subsections alongside their original formulations. The UO formulation of the advective-reflective oscillator (denoted the UARO), which consists of the four UO equations and an additional term describing wave reflection at the eastern boundary, is also discussed.

\section{b. The delayed oscillator}

W01 derives the delayed oscillator from the UO (the UDO) by setting $b_{2}=0$ in Eq. (2), decoupling the system of delay differential equations to yield the following:

$$
\begin{aligned}
& \frac{d T_{3}}{d t}=a \tau_{4}^{x}-b_{1} \tau_{4}^{x}(t-\eta)-\varepsilon T_{3}, \\
& \frac{d \tau_{4}^{x}}{d t}=e T_{3}-R_{\tau_{4}^{r}} \tau_{4}^{x},
\end{aligned}
$$

where $a, b_{1}, e, \varepsilon, R_{\tau_{4}^{k}}$, and $\eta$ are identical to those coefficients in the UO Eqs. (2) and (4).

In the original delayed oscillator equation derived by Battisti and Hirst (1989), the zonal wind stress anomaly averaged in the Niño- $4 *$ region is assumed to be proportional to the SST anomaly averaged in the Niño-3 region $\left[\tau_{4}^{x}=e T_{3} / R_{\tau_{4}^{x}}\right.$, obtained from Eq. (7) by setting $\left.d \tau_{4}^{x} / d t=0\right]$ yielding the following single equation for the SST anomaly tendency

$$
\frac{d T_{3}}{d t}=\frac{a e}{R_{\tau_{4}^{r}}} T_{3}-\frac{b_{1} e}{R_{\tau_{4}^{r}}} T_{3}(t-\eta),
$$

where $a e / R_{\tau_{4}^{r}}$ now parameterizes the Bjerknes positive feedback process and thermodynamic damping and $b_{1} e / R_{\tau_{4}^{x}}$ is the negative feedback term corresponding to term [2] in Eq. (2). We highlight the lack of an explicit damping term $\varepsilon$ in Eq. (8); in the formulation of Battisti and Hirst (1989), the damping term is linear in SST so we incorporate this term into the coefficient $a e / R_{\tau_{4}^{x}}$. Note also that Eq. (8) implicitly includes thermocline depth variability since the thermocline depth anomaly in the eastern Pacific $\left({ }^{\circ} \mathrm{E}\right)$ is proportional to the sum of the instantaneous response to equatorial wind stresses, plus a delayed response due to off-equatorial wind stress curl.

\section{c. The recharge oscillator}

The recharge oscillator model assumes that during an El Niño (La Niña) event, the atmosphere responds 
almost instantaneously to warm (cool) SST anomalies in the central-eastern equatorial Pacific and the resultant change in the wind stress curl incites discharge (recharge) of equatorial heat content (Clarke et al. 2007). Hence, in the derivation of the URO, the anomalous zonal wind stress tendencies in the Niño-4* and Niño-5 regions from Eqs. (4) and (5) are set to zero, yielding

$$
\tau_{4}^{x}=\frac{e}{R_{\tau_{4}^{x}}} T_{3}, \quad \tau_{5}^{x L}=\frac{k}{R_{\tau_{5}^{x}}} h_{6},
$$

where $\tau_{5}^{x L}$ is the low-frequency component of $\tau_{5}^{x}$. These relations are substituted into Eqs. (2) and (3) and, setting each of the delay constants to zero, W01 derives the following coupled system of differential equations for the URO:

$$
\begin{aligned}
& \frac{d T_{3}}{d t}=\frac{a e-b_{1} e}{R_{\tau_{4}^{k}}} T_{3}+\frac{b_{2} k}{R_{\tau_{5}^{k}}} h_{6}-\varepsilon T_{3}, \\
& \frac{d h_{6}}{d t}=-\frac{c e}{R_{\tau_{4}^{x}}} T_{3}-R_{h} h_{6} .
\end{aligned}
$$

Again, the constants $a, b_{1}, b_{2}, e, k, \varepsilon, R_{h}, R_{\tau_{4}^{x}}$, and $R_{\tau_{5}^{x}}$ are identical to those in Eqs. (2)-(5). The term $\left(a e-b_{1} e\right) / R_{\tau_{4}^{x}}$ in Eq. (10) parameterizes growth by the Bjerknes positive feedback and the term $b_{2} k / R_{\tau_{5}^{k}}$ parameterizes thermocline feedback processes. From Eq. (11), ce/ $R_{\tau_{4}^{r}}$ represents Sverdrup transport north and south of the equatorial region, while $R_{h}$ represents damping of thermocline depth anomalies, mediated by upwelling (Mechoso et al. 2003).

The recharge oscillator equations derived by Jin (1997a) can be written

$$
\begin{aligned}
& \frac{d T_{3}}{d t}=\frac{a e-b_{1} e}{R_{\tau_{4}^{x}}} T_{3}+\frac{b_{2} k}{R_{\tau_{5}^{x}}} h_{W}, \\
& \frac{d h_{W}}{d t}=-\frac{c e}{R_{\tau_{4}^{x}}} T_{3}-R_{h} h_{W} .
\end{aligned}
$$

These equations differ from the URO Eqs. (10) and (11) with respect to the region in which the thermocline depth anomaly is defined: while $h_{6}$ in Eq. (10) is averaged off-equatorially in the Niño- $6 *$ region, in Eqs. (12) and (13) the thermocline depth anomaly, denoted $h_{W}$, is averaged in the western equatorial Pacific $\left(5^{\circ} \mathrm{S}-5^{\circ} \mathrm{N}\right.$, $\left.140^{\circ}-180^{\circ} \mathrm{E}\right)$. We choose to average $h_{W}$ between $140^{\circ}$ and $180^{\circ} \mathrm{E}$, rather than in the Niño- 4 region, to be consistent with previous studies (Mechoso et al. 2003; Bettio 2007 ) and to capture the majority of the variability in the thermocline depth anomalies (Fig. 1). Similar to the original delayed oscillator equations, the damping term $\varepsilon T_{3}$ from Eq. (10) is not explicit in Eq. (12).

\section{d. The western Pacific oscillator}

W01 derives the UWPO SST anomaly equation from the UO by setting $b_{1}$ in Eq. (2) to zero, yielding

$$
\frac{d T_{3}}{d t}=a \tau_{4}^{x}+b_{2} \tau_{5}^{x}(t-\delta)-\varepsilon T_{3} .
$$

The remaining equations for thermocline depth and zonal wind stress anomalies are identical to the UO Eqs. (3)-(5).

By contrast with the UWPO, the original western Pacific oscillator does not explicitly take into account SST anomalies, instead including prognostic equations for thermocline depth anomalies in the eastern equatorial and western off-equatorial Pacific (Weisberg and Wang 1997). The original model comprises a system of four delay differential equations:

$$
\begin{aligned}
& \frac{d h_{3}}{d t}=a^{h} \tau_{4}^{x}+b_{2}^{h} \tau_{5}^{x}(t-\delta)-\varepsilon^{h} h_{3}, \\
& \frac{d h_{6}}{d t}=-c \tau_{4}^{x}(t-\lambda)-R_{h} h_{6}, \\
& \frac{d \tau_{4}^{x}}{d t}=e^{h} h_{3}-R_{\tau_{4}^{x}}^{h} \tau_{4}^{x}, \\
& \frac{d \tau_{5}^{x}}{d t}=k h_{6}-R_{\tau_{5}^{x}} \tau_{5}^{x},
\end{aligned}
$$

where the coefficients $c, k, R_{h}$, and $R_{\tau_{5}^{\mathrm{r}}}$ are identical to those in the UO Eqs. (3) and (5), and the remaining constants $a^{h}, b_{2}^{h}, e^{h}, \varepsilon^{h}$, and $R_{\tau_{4}^{x}}^{h}$ have similar physical interpretations to their counterparts in Eqs. (4) and (14) that were parameterized in terms of $T_{3}$. The variable $h_{3}$ denotes the Niño-3 averaged equatorial thermocline depth anomaly while the variable $h_{6}$ denotes the Niño-6* off-equatorial thermocline depth anomaly. In the original formulation, the damping terms were cubic. However, the linear and cubic forms of the damping terms do not result in significantly different estimates for the coefficients, so we adopt only linear forms here.

\section{e. The advective-reflective oscillator}

While the advective-reflective oscillator was well described by Picaut et al. (1997), W01 first defined the UARO in a system of delay differential equations. In W01, the UARO model couples Eqs. (3)-(5) of the UO with the following equation for the Niño-3 SST anomaly tendency:

$\frac{d T_{3}}{d t}=a \tau_{4}^{x}-b_{1} \tau_{4}^{x}(t-\eta)+b_{2} \tau_{5}^{x}(t-\delta)-b_{3} \tau_{4}^{x}(t-\mu)-\varepsilon T_{3}$,

where all but the fourth term on the right-hand side of Eq. (19), which represents wave reflection at both the 
eastern and western boundaries of the Pacific, are identical to the terms in Eq. (2).

\section{Analysis of the conceptual models}

Table 1 summarizes the main results from the GLS fits of the UO and conceptual models it attempts to unify, as well as the original versions of the delayed, recharge, and western Pacific oscillators. The calculated rmse values and explained variances $\rho^{2}$ are also reported.

\section{a. SST tendency equations}

\section{1) UNIFIED OSCILLATOR AND UNDERPINNING MODELS}

We first consider how well the UO equation captures the SST anomaly tendency in the ACCESS-OM simulation using 1) the parameter values given by W01 and 2) the parameter values estimated via GLS regression to the model data.

The W01 curve provides a poor fit to the model $d T_{3} / d t$ $\left(\mathrm{rmse}=0.68^{\circ} \mathrm{Cmonth}^{-1}, \rho^{2}=11 \%, d t=1\right.$ month $)$, overestimating many of the positive and negative feedbacks in Eq. (2) (note that the W01 coefficients are converted to units of months). This is particularly evident for the western Pacific oscillator negative feedback coefficient $b_{2}$, which is over 40 times the size of the GLS estimate. The W01 value for the Bjerknes positive feedback coefficient $a$ and the delayed oscillator negative feedback coefficient $b_{1}$ are of a similar order to the fitted values [W01 derives the latter two values from Battisti and Hirst (1989)].

By contrast with the W01 curve, there is a much closer fit between the curve obtained using GLS regression analysis and the model $d T_{3} / d t\left(\mathrm{rmse}=0.055^{\circ} \mathrm{Cmonth}^{-1}\right.$, $\rho^{2}=50 \%$; Fig. 7a). However, it is possible that the GLS analysis results in an overfitting of the UO equation. To test this hypothesis, the individual balance relations used in W01 to derive the UO Eq. (2)-namely, Eqs. (A1) and (A2) from the appendix-are refit to the ACCESS-OM simulation data. The coefficients estimated from these equations, and the corresponding compiled estimates for the UO coefficients $a, b_{1}$, and $b_{2}$, are compared with the values estimated directly from Eq. (2) in Table 2. The two fitting methods result in considerably different values for the coefficients, with differences of up to four orders of magnitude between the two estimates. The GLS analysis of Eq. (A4) results in a value for $\beta$ that is statistically indistinguishable from zero, leading to a fitted curve explaining $72 \%$ of the variance in $h_{3}$ calculated directly from ACCESS-OM $\left(\right.$ rmse $\left.=0.29^{\circ} \mathrm{C}\right)$.
Next, the UO component oscillators are fit to $d T_{3} / d t$ from the ACCESS-OM simulation data using GLS regression (Fig. 8). In each case we use the formulation of the individual oscillators derived from the UOnamely, the UARO, UDO, URO, and UWPO-rather than their original formulations (which are discussed in the following subsection). Compared with the UO, the UDO, and UARO models provide significantly better fits to $d T_{3} / d t$ calculated directly from ACCESSOM $\left(\rho^{2}=58 \%\right.$ and $\rho^{2}=56 \%$, for the UDO and UARO models, respectively. Significance was measured using a two-sided Student's $t$ test, resulting in $p<0.0001$ in each case). We note that it is expected that the UARO model provides a better fit than the UO, since the UARO model adds a parameter to the UO. The fit of the URO returns a value for $\left(a-b_{1}\right) e / R_{\tau_{4}^{x}}$ that is trivial (statistically indistinguishable from zero), leading to a fitted curve that explains essentially none of the variance in the simulated tendency. The poor fit of Eq. (10) is most likely due to the thermocline depth anomaly being defined off equator rather than on equator, as discussed in the following subsection.

For a delay term $\delta$ of 3 months, and assuming an $\operatorname{AR}(2)$ error correlation structure, the UWPO coefficients found by GLS regression of Eq. (14) result in a fitted curve explaining $14 \%$ of the variance in the model $d T_{3} / d t$. Although this does not necessarily imply that the western Pacific oscillator negative feedback mechanism is unimportant in modeling the behavior of ENSO, we note that the UO and UARO weight the coefficient $b_{2}$ as least important in contributing to the transition of an ENSO event. It is possible that the UWPO negative feedback is incorrect or ill suited to the actual physical mechanism operating in ACCESS-OM.

Based on these fits we perform a quick ranking of the relative importance of each of the mechanisms described in the UO and its underpinning models. The UWPO term describing locally forced eastwardpropagating Kelvin waves is weighted as the least important mechanism in the UO and UARO compared with the delayed and advective-reflective negative feedbacks. The inclusion of a term parameterizing the Niño-5 zonal wind stress anomalies in Eq. (A4) used to derive the UO SST anomaly tendency equation is not a significant improvement over the relation with this term omitted. A similar result is found by comparing the fits of the UO and UDO equations for the SST anomaly tendencies. We conclude, then, that the UWPO mechanism for ENSO decay is the least important in describing the ENSO behaviors simulated by ACCESS-OM. With a delay term of $\eta=2$ or 3 months, the UDO Eq. (6) can be used to assess the accuracy of 
TABLE 1. Regression coefficients obtained via GLS regression of the UO, Eqs. (2)-(5), and the original and UO versions of the delayed, recharge, western Pacific, and advective-reflective oscillators, Eqs. (6)-(19). In each case, the "U" prefix denotes a model that has been derived from the UO. The explained variance $\left(\rho^{2}\right)$ of the fitted curves to the model tendencies along with the corresponding rmse values estimated via cross validation are reported. The parameters in W01 are also listed. Coefficients marked with an asterisk are derived from the original WPO equation for Niño-3 $\left(5^{\circ} \mathrm{S}-5^{\circ} \mathrm{N}, 150^{\circ}-90^{\circ} \mathrm{W}\right)$ thermocline depth and have different units to the corresponding fitted values from other models [see Eq. (15)]. Coefficients marked with a cross are derived from the original WPO equation for Niño- $4^{*}\left(5^{\circ} \mathrm{S}-5^{\circ} \mathrm{N}\right.$, $150^{\circ} \mathrm{E}-160^{\circ} \mathrm{W}$ ) zonal wind stress, parameterized in terms of the Niño-3 thermocline depth, and have different units to the corresponding fitted values from other models [see Eq. (18)].

\begin{tabular}{|c|c|c|c|c|c|c|c|c|c|}
\hline Constant & $\mathrm{UO}$ & UDO & DO & URO & $\mathrm{RO}$ & UWPO & WPO & UARO & W01 \\
\hline \multicolumn{10}{|l|}{ SST equations: $d T_{3} / d t$} \\
\hline$b_{1}\left[{ }^{\circ} \mathrm{C}\left(\mathrm{N} \mathrm{m}^{-2}\right)^{-1}\right.$ month $\left.^{-1}\right]$ & $\begin{array}{l}14 \\
19\end{array}$ & $\begin{array}{l}11 \\
16\end{array}$ & - & - & - & $\begin{array}{r}2.8 \\
-\end{array}$ & $\begin{array}{l}0^{*} \\
-\end{array}$ & $\begin{array}{c}13 \\
5.3\end{array}$ & $\begin{array}{l}13 \\
21\end{array}$ \\
\hline$b_{2}\left[{ }^{\circ} \mathrm{C}\left(\mathrm{N} \mathrm{m}^{-2}\right)^{-1}\right.$ month $\left.^{-1}\right]$ & 1.5 & - & - & - & - & 1.8 & $8.6^{*}$ & 0.99 & 63 \\
\hline$b_{3}\left[{ }^{\circ} \mathrm{C}\left(\mathrm{N} \mathrm{m}^{-2}\right)^{-1}\right.$ month $\left.^{-1}\right]$ & - & - & - & - & - & - & - & 12 & 21 \\
\hline$a e / R_{\tau_{4}^{x}}\left(\right.$ month $\left.^{-1}\right)$ & - & - & 0.91 & - & - & - & - & - & - \\
\hline$b_{1} e / R_{\tau_{4}^{x}}\left(\right.$ month $\left.^{-1}\right)$ & - & - & 0.93 & - & - & - & - & - & - \\
\hline$\left(a-b_{1}^{4}\right) e / R_{\tau_{4}^{r}}\left(\right.$ month $\left.^{-1}\right)$ & - & - & - & 0 & 0.066 & - & - & - & - \\
\hline$b_{2} k / R_{\tau_{5}^{k}}\left(\right.$ month $\left.^{-1}\right)$ & - & - & - & 0.013 & 0.18 & - & - & - & - \\
\hline$\varepsilon\left(\right.$ month $\left.^{-1}\right)$ & 0 & 0 & - & - & - & 0.025 & $0^{*}$ & 0 & 0.10 \\
\hline$\eta$ (months) & 4 & 5 & 1 & - & - & - & - & 5 & 5 \\
\hline$\delta$ (months) & 3 & - & - & - & - & 3 & $3^{*}$ & 2 & 1 \\
\hline$\mu$ (months) & - & - & - & - & - & - & - & 4 & 3 \\
\hline$\rho^{2}(\%)$ & 50 & 58 & 99 & $\approx 0$ & 35 & 14 & $11^{*}$ & 56 & 11 \\
\hline Rmse $\left({ }^{\circ} \mathrm{C}\right.$ month $\left.^{-1}\right)$ & 0.055 & 0.052 & 0.011 & 0.10 & 0.076 & 0.093 & $0.070 *$ & 0.046 & 0.68 \\
\hline \multicolumn{10}{|l|}{ Thermocline equations: $d h_{6} / d t$} \\
\hline$c\left[{ }^{\circ} \mathrm{C}\left(\mathrm{N} \mathrm{m}^{-2}\right)^{-1}\right.$ month $\left.^{-1}\right]$ & 0 & - & - & - & - & 0 & 0 & 0 & 6.3 \\
\hline$c e / R_{\tau_{4}^{x}}\left(\right.$ month $\left.^{-1}\right)$ & - & - & - & 0.0034 & 0.071 & - & - & - & - \\
\hline$R_{h}\left(\right.$ month $\left.^{-1}\right)$ & 0 & - & - & 0.042 & 0.068 & 0 & 0 & 0 & 0.42 \\
\hline$\lambda$ (months) & 6 & - & - & - & - & 6 & 6 & 6 & 6 \\
\hline$\rho^{2}(\%)$ & 0 & - & - & 4.6 & 54 & 0 & 0 & 0 & 0.11 \\
\hline Rmse $\left({ }^{\circ} \mathrm{C}\right.$ month $\left.{ }^{-1}\right)$ & 0.039 & - & - & 0.040 & 0.043 & 0.039 & 0 & 0.039 & 0.16 \\
\hline \multicolumn{10}{|c|}{ Niño-4* wind stress equations: $d \tau_{4}^{x} / d t$} \\
\hline$e\left(\mathrm{~N} \mathrm{~m}^{-2}{ }^{\circ} \mathrm{C}^{-1} \mathrm{month}^{-1}\right)$ & 0 & 0 & - & - & - & 0 & $0.0015^{+}$ & 0 & 0.0030 \\
\hline$e / R_{\tau_{4}^{x}}\left(\mathrm{~N} \mathrm{~m}^{-2}{ }^{\circ} \mathrm{C}^{-1}\right)$ & - & - & 0.0096 & 0.0096 & 0.0096 & - & - & - & - \\
\hline$R_{\tau_{4}^{r}}\left(\right.$ month $\left.^{-1}\right)$ & 0.032 & 0.032 & - & - & - & 0.032 & $0.13^{+}$ & 0.032 & 0.17 \\
\hline$\rho^{2}(\%)$ & 0.00013 & 0.00013 & 58 & 58 & - & 0.00013 & $1.0^{+}$ & 0.00013 & 2.9 \\
\hline Rmse $\left(\mathrm{N} \mathrm{m}^{-2}\right.$ month $\left.^{-1}\right)$ & 0.0010 & 0.0010 & 0.0059 & 0.0059 & - & 0.0010 & $0.0012^{+}$ & 0.0010 & 0.0020 \\
\hline \multicolumn{10}{|c|}{ Niño-5 wind stress equations: $d \tau_{5}^{x} / d t$} \\
\hline$k\left(\mathrm{~N} \mathrm{~m}^{-2}{ }^{\circ} \mathrm{C}^{-1}\right.$ month $\left.^{-1}\right)$ & 0.00054 & - & - & - & - & 0.00054 & 0.00054 & 0.00054 & 0.0050 \\
\hline$k / R_{\tau_{5}^{r}}\left(\mathrm{~N} \mathrm{~m}^{-2 \circ} \mathrm{C}^{-1}\right)$ & - & - & - & 0.0098 & - & - & - & - & - \\
\hline$R_{\tau_{5}^{r}}\left(\right.$ month $\left.^{-1}\right)$ & 0.0051 & - & - & - & - & 0.0051 & 0.0051 & 0.0051 & 0.17 \\
\hline$\rho^{2}(\%)$ & 0.0013 & - & - & 3.5 & - & 0.0013 & 0.0013 & 0.0013 & 0.0052 \\
\hline Rmse $\left(\mathrm{N} \mathrm{m}^{-2}\right.$ month $\left.^{-1}\right)$ & 0.00069 & - & - & 0.0066 & - & 0.00069 & 0.00069 & 0.00069 & 0.0031 \\
\hline
\end{tabular}

the UARO mechanism describing the importance of local mean and anomalous zonal advection at the edge of the western Pacific warm pool. GLS fitting using values for the delay term equal to 2 and 3 months, respectively, is unable to return values for the damping term $\varepsilon$ that are statistically distinguishable from zero. Furthermore, the rmses of the fitted curves to both values of the delay term are higher than those for $\eta=5\left(\mathrm{rmse}=0.066^{\circ} \mathrm{Cmonth}^{-1}\right.$, for $\eta=2$; rmse $=0.064^{\circ} \mathrm{Cmonth}^{-1}$, for $\eta=3$ ). Hence, we conclude that the UDO feedback mechanism in the $\mathrm{UO}$ and its underpinning models is the most important in contributing to ENSO growth and decay, followed by the UARO feedback mechanism and the UWPO feedback mechanism.

\section{2) THE ORIGINAL MODELS}

The original delayed oscillator Eq. (8) provides a very close fit to the simulated tendency estimated directly from ACCESS-OM. The rmse is minimized for $\eta=1$ months, leading to the fitted curve explaining $99 \%$ of the variance of the modeled $d T_{3} / d t$. This value for the delay term, $\eta=1$ month, is considerably smaller than the 


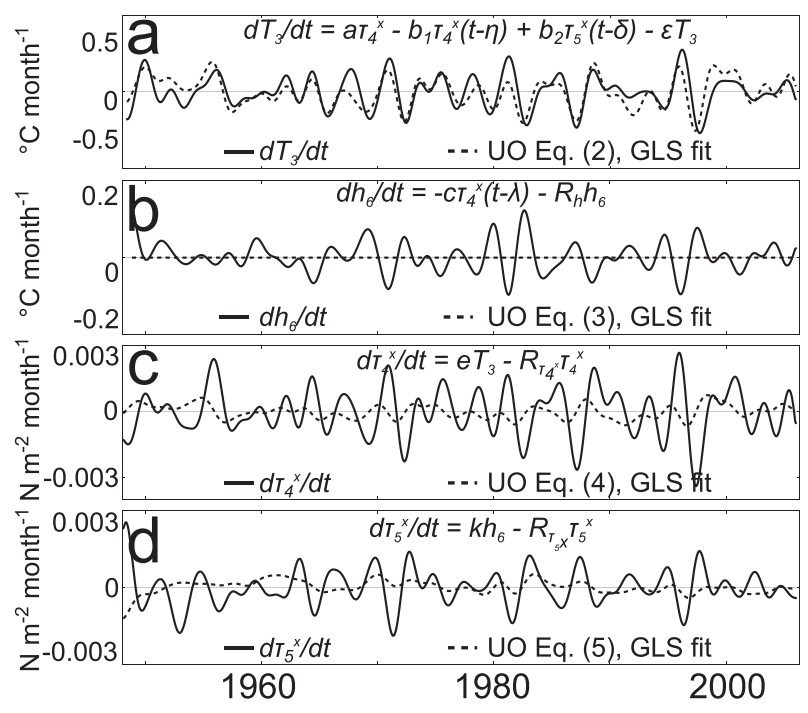

FIG. 7. Fitted and predicted curves for the UO model using ACCESS-OM. In each panel, the solid black line is the tendency determined directly from ACCESS-OM, and the dashed line is the tendency calculated from the right-hand side of the relevant equation where the coefficients are estimated via GLS regression. All data are filtered with a 12-month Parzen filter prior to fitting: (a) the Niño-3 $\left(5^{\circ} \mathrm{S}-5^{\circ} \mathrm{N}, 150^{\circ}-90^{\circ} \mathrm{W}\right) \mathrm{SST}$ anomaly tendency $d T_{3} / d t$ calculated from the UO Eq. (2); (b) the Niño- $6^{*}\left(8^{\circ}-16^{\circ} \mathrm{N}, 150^{\circ}-\right.$ $\left.170^{\circ} \mathrm{E}\right)$ thermocline depth anomaly tendency $d h_{6} / d t$ calculated from the UO Eq. (3); (c) the Niño- $4^{*}\left(5^{\circ} \mathrm{S}-5^{\circ} \mathrm{N}, 150^{\circ} \mathrm{E}-160^{\circ} \mathrm{W}\right)$ zonal wind stress anomaly tendency $d \tau_{4}^{x} / d t$ calculated from the UO Eq. (4); and (d) the Niño-5 $\left(5^{\circ} \mathrm{S}-5^{\circ} \mathrm{N}, 120^{\circ}-140^{\circ} \mathrm{E}\right)$ zonal wind stress anomaly tendency $d \tau_{5}^{\chi} / d t$ calculated from the UO Eq. (5). Note that since the coefficients from Eq. (3) estimated using GLS are statistically indistinguishable from zero, the thick line is equal to zero in (b).

values given in Battisti and Hirst (1989), of $\eta=6$ months, and W01, of $\eta=5$ months. When a delay value of $\eta=5$ (consistent with W01) is used to fit the original delayed oscillator, the resulting fitted curve explains $94 \%$ of the variance in $d T_{3} / d t$ calculated directly from ACCESS-OM (the rmse is $0.052^{\circ} \mathrm{Cmonth}^{-1}$ ). It is not surprising that the delayed oscillator Eq. (8) provides such a close estimate of the modeled $d T_{3} / d t$; indeed, the tendency term on the left-hand side of Eq. (8) is directly proportional to the right-hand side, regardless of the value of the delay parameter $\eta$. When Eq. (8) is refit to the simulated $d T_{3} / d t$ with $\tau_{4}^{x}$ substituted for $T_{3}$ on the righthand side of the equation, the result is poorer than that equation with $T_{3}$ instead of $\tau_{4}^{x}$ (rmse $=0.054^{\circ} \mathrm{C}$ month $^{-1}$, $\rho^{2}=71 \%$, for $\eta=3$ months), which indicates that the relation $5^{\circ} \mathrm{S}$ is incomplete, as discussed in section $4 \mathrm{c}$.

The values of the recharge oscillator coefficients estimated via GLS regression are similar to those of previous studies (e.g., Mechoso et al. 2003). However, the fitted curve here explains only $35 \%$ of the variance in the
TABLE 2. Regression coefficients obtained via GLS regression of the individual balance relations Eqs. (A1) and (A4) in the appendix, and the derived values for the constants $a, b_{1}$, and $b_{2}$ from these individual balance relations, compared with the constants estimated directly from the UO Eq. (2). The explained variance $\left(\rho^{2}\right)$ of the fitted curves to the model tendencies along with the corresponding rmse values, estimated using cross validation, are reported.

\begin{tabular}{lcc}
\hline \hline \multicolumn{1}{c}{ Constants } & $\begin{array}{c}\text { Eqs. (A1) } \\
\text { and (A4) }\end{array}$ & UO Eq. (2) \\
\hline$R\left[{ }^{\circ} \mathrm{C}\left(\mathrm{N} \mathrm{m}^{-2}\right)^{-1} \mathrm{month}^{-1}\right]$ & 15 & - \\
$K_{E}\left(\mathrm{month}^{-1}\right)$ & 0.26 & - \\
$\rho^{2}(\%)$ & 3.6 & - \\
$\mathrm{Rmse}\left({ }^{\circ} \mathrm{C} \mathrm{month}{ }^{-1}\right)$ & 0.10 & - \\
$\alpha\left[{ }^{\circ} \mathrm{C}\left(\mathrm{N} \mathrm{m}^{-2}\right)^{-1}\right]$ & 50 & - \\
$\gamma\left[{ }^{\circ} \mathrm{C}\left(\mathrm{N} \mathrm{m}^{-2}\right)^{-1}\right]$ & 12 & - \\
$\beta\left[{ }^{\circ} \mathrm{C}\left(\mathrm{N} \mathrm{m}^{-2}\right)^{-1}\right]$ & 0 & - \\
$\eta(\mathrm{months})$ & 8 & - \\
$\delta(\mathrm{months})$ & 1 & - \\
$\rho^{2}(\%)$ & 72 & 8.8 \\
$\mathrm{Rmse}\left({ }^{\circ} \mathrm{C}\right)$ & 0.29 & 13 \\
$a=R+\alpha K_{E}$ & 28 & 1.1 \\
$b_{1}=\gamma K_{E}$ & 2.9 & \\
$b_{2}=\beta K_{E}$ & 0 & - \\
\hline
\end{tabular}

model $d T_{3} / d t$, for an rmse of $0.076^{\circ} \mathrm{Cmonth}^{-1}$ (Fig. 9a). The original recharge oscillator SST equation performs considerably better than the URO, the difference being due to the averaging regions for the thermocline depth anomalies and the omission of an explicit damping term in the original equation.

The recharge oscillator equation for $d T_{3} / d t$ has particularly poor closure during the period $1990-95$, as previously shown by Graham et al. (2014). However, the years 1990-95 in ACCESS-OM are marked by central Pacific ENSO events, the mechanisms of which are not well described by the recharge oscillator model (Kug et al. 2010; Yeh et al. 2014). That is, the recharge oscillator assumes that the primary development and decay dynamics of ENSO are related to the shoaling and deepening of the equatorial thermocline, which is not necessarily the case for central Pacific ENSO events (Singh and Delcroix 2013; Yeh et al. 2014). It is for this reason that the variances explained by the recharge model fitted curves for $d T_{3} / d t$ (and $d h_{W} / d t$ in the following subsection) are relatively low.

Note that our results do not imply that the delayed oscillator is a superior diagnostic than the recharge oscillator. For example, the decay of El Niño events, rather than their growth, might be better described in the delayed oscillator (Li and Clarke 1994; Mantua and Battisti 1994), which may be partly due to the omission of noise forcing that is important in the excitation of ENSO events (Vecchi et al. 2006). Mechoso et al. (2003) found that the 


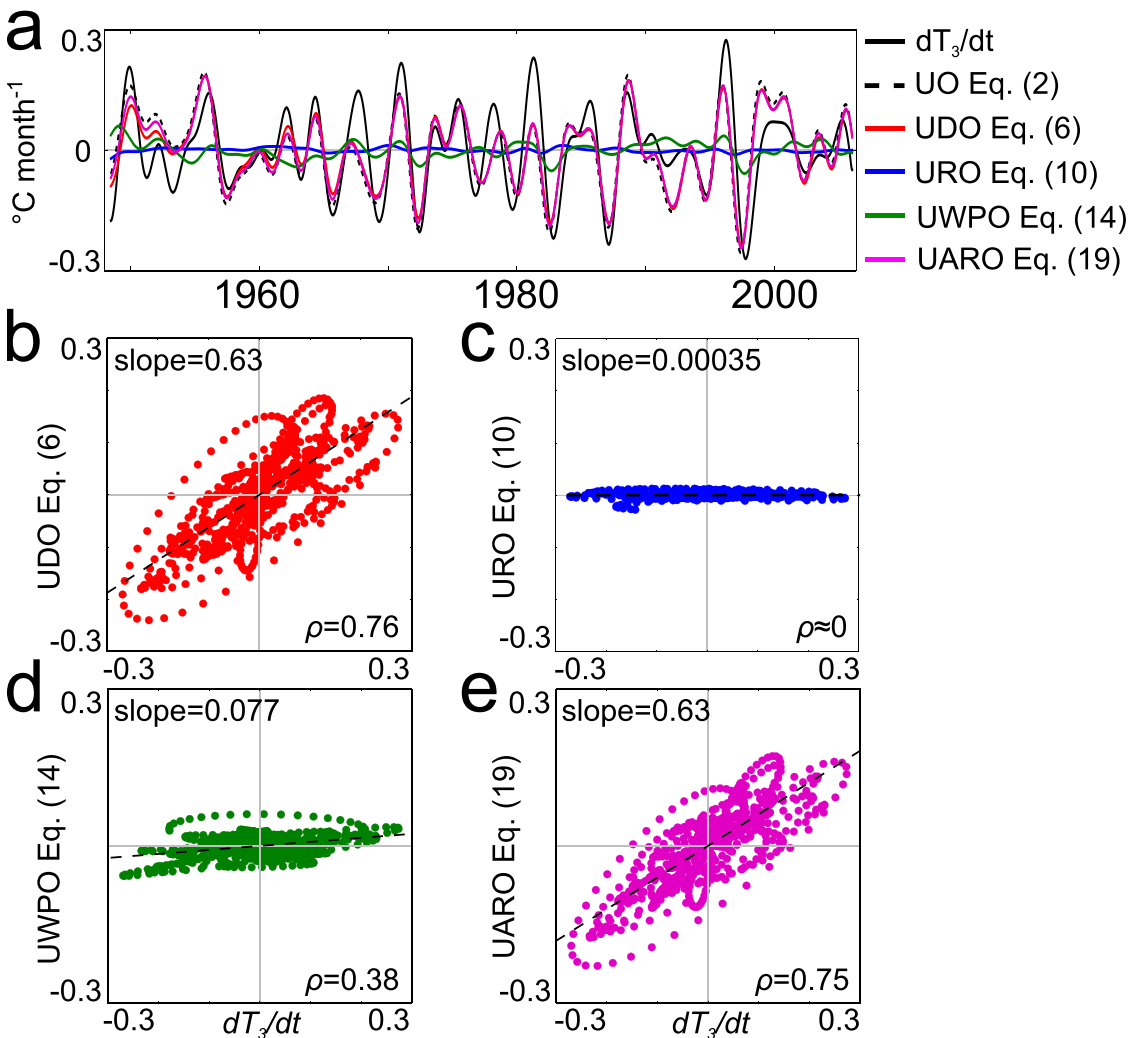

FIG. 8. Comparison of the fits to the ACCESS-OM SST anomaly tendency $d T_{3} / d t$ by each of the UO component oscillators where the coefficients are estimated using GLS regression. (a) The black line is $d T_{3} / d t$ determined directly from ACCESS-OM. The red line corresponds to the righthand side of Eq. (6) for UDO, the dark blue line corresponds the right-hand side of Eq. (10) for URO, the green line corresponds to the right-hand side of Eq. (14) for UWPO, and the magenta line corresponds to the right-hand side of Eq. (19) for UARO. (b)-(e) Scatterplots of $d T_{3} / d t$ $\left({ }^{\circ} \mathrm{C}\right.$ month $\left.{ }^{-1}\right)$ determined directly from ACCESS-OM ( $x$ axis) against $d T_{3} / d t\left({ }^{\circ} \mathrm{C}\right.$ month $\left.^{-1}\right)$ calculated from the UDO (red), URO (dark blue), UWPO (green), and UARO (magenta). In (b)-(e), $\rho$ is the correlation coefficient between $d T_{3} / d t$ determined directly from ACCESS-OM and the corresponding tendency calculated from each of the underpinning models.

capabilities of the delayed and recharge oscillator models in capturing the behavior of the ENSO cycle extracted from a CGCM were essentially indistinguishable. That our results differ from those of Mechoso et al. (2003) might be due to the different filtering techniques used. While Mechoso et al. (2003) fitted the delayed and recharge oscillators to CGCM data that included only variability on time scales of 2-7 years, we did not filter out lower frequency variability in our analysis, which may impact the performance of the recharge oscillator. Furthermore, prior to CMIP5, most CGCMs tended to simulate a single type of El Niño-the eastern Pacific spatial flavor-and did not simulate the central Pacific El Niño well (Yu and Kim 2010; Ham and Kug 2012; Kug et al. 2012), which may have led to a better performance of the recharge oscillator relative to the delayed oscillator in Mechoso et al. (2003).
A study by Bettio (2007) examined the skill of the delayed and recharge oscillator frameworks in diagnosing the ENSO behavior of the Australian BMRC CGCM (Power et al. 2006) compared with observations. Bettio (2007) found that the delayed oscillator demonstrated superior skill over the recharge oscillator in capturing ENSO behavior when applied to the BMRC CGCM. Bettio (2007) argues that eastern equatorial upwelling processes (here represented in the coefficient $R_{h}$ ) are less efficient at explaining the majority of the variability in eastern equatorial SST anomalies in their model compared with observations. A similar result is possible here for the ACCESS-OM data, particularly given the presence of a cold tongue bias in the central-eastern equatorial Pacific (Fig. 2), which can develop because of biases in upwelling that result from excessively strong trade winds (Vannière et al. 2013). For 

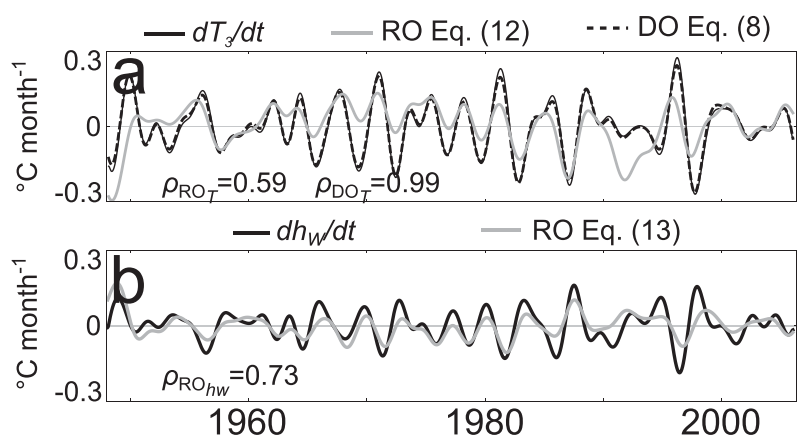

FIG. 9. Fitted and predicted curves for the original delayed and recharge oscillator models using ACCESS-OM. (a) The solid black line is $d T_{3} / d t$ determined directly from ACCESS-OM. The dashed black line corresponds to the tendency calculated from the righthand side of the original delayed oscillator equation for $T_{3}$, namely, Eq. (8), with a delay $\eta$ of 1 month and where the coefficients are estimated using GLS regression (column 3, Table 1). The solid gray line corresponds to the tendency calculated from the right-hand side of the original recharge oscillator equation for $T_{3}$, namely, Eq. (12), where the coefficients are estimated using GLS regression (column 5, Table 1). (b) The solid black line is $d h_{W} / d t$ determined directly from ACCESS-OM. The solid gray line corresponds to the tendency calculated from the right-hand side of the original recharge oscillator equation for $h_{W}$, namely, Eq. (13), where the coefficients are estimated using GLS regression (column 5, Table $1)$. In each panel, the correlation coefficients $(\rho)$ between the delayed and recharge oscillator tendency equations and the corresponding tendency calculated from ACCESS-OM are reported.

this reason, it is difficult to determine from the analysis here which of the delayed and recharge oscillator mechanisms for negative feedback is more realistic.

\section{b. Thermocline tendency equations}

\section{1) UNIFIED OSCILLATOR AND UNDERPINNING MODELS}

We next consider the extent to which the UO prognostic equation for thermocline depth anomaly Eq. (3) captures the behavior of $d h_{6} / d t$ calculated directly from the ACCESS-OM data. W01 defined the thermocline depth using the $20^{\circ} \mathrm{C}$ isotherm, while here we use the depth-averaged temperature above $300 \mathrm{~m}$. Hence, to evaluate the skill of the W01 curve, using the W01 coefficients, Eq. (3) [and term 1 on the right-hand side of Eq. (5)] is divided by $20^{\circ} \mathrm{Cm}^{-1}$ (i.e., the regression coefficient estimated in section 2 relating the depthaveraged temperature above $300 \mathrm{~m}$ to the $20^{\circ} \mathrm{C}$ isotherm depth). The W01 coefficients are also converted to units of months. The W01 curve poorly emulates the behavior of the simulated tendency $d h_{6} / d t\left(\mathrm{rmse}=0.16^{\circ} \mathrm{Cmonth}^{-1}\right.$, $\left.\rho^{2}=0.11 \%\right)$.

The GLS regression fit of Eq. (3) to the ACCESS-OM $d h_{6} / d t$ (identical to the UWPO and UARO thermocline equations) returns trivial values for the coefficient $c$ when $\lambda=0,1, \ldots, 10$ months, leading to a fitted curve that explains essentially none of the variance in the model $d h_{6} / d t$. When the URO thermocline depth anomaly tendency Eq. (11) is fit to the simulated $d h_{6} / d t$, a similar result to that of the UO Eq. (3) is obtained $\left(\mathrm{rmse}=0.040^{\circ} \mathrm{C}_{\text {month }}{ }^{-1}, \rho^{2}=4.6 \%\right)$.

While in W01 the UO Eq. (2) for $d T_{3} / d t$ is derived using a series of balance relations, Eq. (3) for $d h_{6} / d t$ is inferred directly from the off-equatorial vorticity equation (appendix). As such, a similar procedure of fitting the individual balance relations as in the previous subsection for the UO equation for $d T_{3} / d t$ is not applicable here.

\section{2) THE ORIGINAL MODELS}

For the original recharge oscillator thermocline depth anomaly tendency, the fitted curve explains $54 \%$ of the variance in the model $d h_{W} / d t$ (Fig. 9b). Hence, the original recharge oscillator prognostic thermocline depth anomaly equation provides a considerably better fit to the simulated tendency than both the UO and the URO. Comparing Eqs. (11) and (13), we observe that the better fit for the original model is primarily the result of a more appropriate averaging region for the thermocline depth anomaly. In the original recharge oscillator, $h_{W}$ represents equatorial western Pacific thermocline depth anomalies, whereas $h_{6}$ in the URO represents offequatorial western Pacific thermocline depth anomalies. W01 argues that since the maximum interannual variability in the thermocline depth anomaly is in the offequatorial western Pacific region, the variable $h_{6}$ in the UO equations should be averaged over the Niño-6* region, rather than over the equatorial western Pacific. However, the mechanism governing ENSO growth and transition in the recharge oscillator requires the discharge and recharge of equatorial heat content, which is consistent with observations (e.g., Meinen and McPhaden 2000), implying that the thermocline depth anomaly in the western Pacific is more appropriately averaged on, rather than off, the equator.

In the original western Pacific oscillator, there are two prognostic equations for thermocline depth: one for the Niño-3 (i.e., equatorial) thermocline depth anomaly, Eq. (15), and the other for the Niño-6* thermocline depth anomaly, Eq. (16), which is identical to the UO Eq. (3). The right-hand side of Eq. (15) is fit to the ACCESS-OM output, finding that the coefficients $a^{h}$ and $\varepsilon^{h}$ are statistically indistinguishable from zero. The GLS regression fit of Eq. (15) to the simulated $d h_{3} / d t$ is consistent with the poor fits of the UWPO's prognostic equation for the SST anomaly tendency, Eq. (14), and the western Pacific negative feedback mechanism in Eq. (2). 


\section{c. Niño-4* zonal wind stress tendency equations}

There are three versions of equations for $\tau_{4}^{x}$ among the UO, its underpinning models, and the original versions of these models: a prognostic version, as in the UO, in terms of $T_{3}$ and $\tau_{4}^{x}$; a diagnostic version that relates $\tau_{4}^{x}$ directly to $T_{3}$, as in the recharge oscillator and the original delayed oscillator; and a prognostic version in terms of $h_{6}$ and $\tau_{4}^{x}$, as in the original western Pacific oscillator.

We first consider the prognostic UO Eq. (4) for the Niño-4* zonal wind stress anomaly tendency. Applying the W01 parameter values as coefficients to this equation results in a curve that is unable to replicate $d \tau_{4}^{\chi} / d t$ calculated from ACCESS-OM; the correlation between the two curves is -0.17 . The GLS regression analysis applied to Eq. (4) does not improve the fit, returning a trivial value for $e\left(\mathrm{rmse}=1.0 \times 10^{-3} \mathrm{~N} \mathrm{~m}^{-2}\right.$ month $^{-1}$, $\rho^{2} \approx 0 \%$; Fig. $7 \mathrm{c}$ ). We hypothesize that the tendency term in Eq. (4) is unnecessary and that the dominant balance is simply between the Niño- $4 *$ zonal wind stress anomaly and the Niño-3 SST anomaly. To test this hypothesis, we rearrange Eq. (4) as follows:

$$
\tau_{4}^{x}=\frac{e}{R_{\tau_{4}^{x}}} T_{3}-\frac{1}{R_{\tau_{4}^{x}}} \frac{d \tau_{4}^{x}}{d t},
$$

and apply GLS regression analysis. We find that the coefficient $1 / R_{\tau_{4}^{x}}$ in front of the tendency term is statistically indistinguishable from zero, which indicates that it is not linearly correlated with the model state and can be treated as noise. The dominant balances in Eq. (20) are illustrated in Fig. 10a. The fit for Eq. (9) between $\tau_{4}^{x}$ and $T_{3}$ produces similar results to that of Eq. (20) $\left(\right.$ rmse $=0.0059 \mathrm{~N} \mathrm{~m}^{-2}$ month $\left.^{-1}, \rho^{2}=58 \%\right)$. However there is clear structure in the residual of Eqs. (9) and (20) when the tendency term is omitted (i.e., $\tau_{4}^{x}-e T_{3} / R_{\tau_{4}^{x}}$ ), with coherent peaks and troughs corresponding to $\mathrm{El}$ Niño and La Niña years, which is indicative of nonlinearity in the dependence of $\tau_{4}^{x}$ on $T_{3}$.

Given the importance of atmospheric nonlinearities in parameterizing processes such as westerly wind bursts and the Madden-Julian oscillation as well as the super El Niño events of 1982-83 and 1997-98 (Vecchi et al. 2006; Levine and Jin 2010; Choi et al. 2013), the inclusion of nonlinearity in Eq. (9) may improve the fit. A suitable candidate is a piecewise nonlinearity, which has been found to aid in replicating the asymmetries in ENSO amplitude, sequencing, and timing (Choi et al. 2013). We note that previous studies have also extended the simple steady state atmospheric model above to include time dependence between $\tau_{4}^{x}$ and $T_{3}$, since wind stress anomalies have been demonstrated to adjust to SST on the order of a month or so (Neelin et al. 2000;
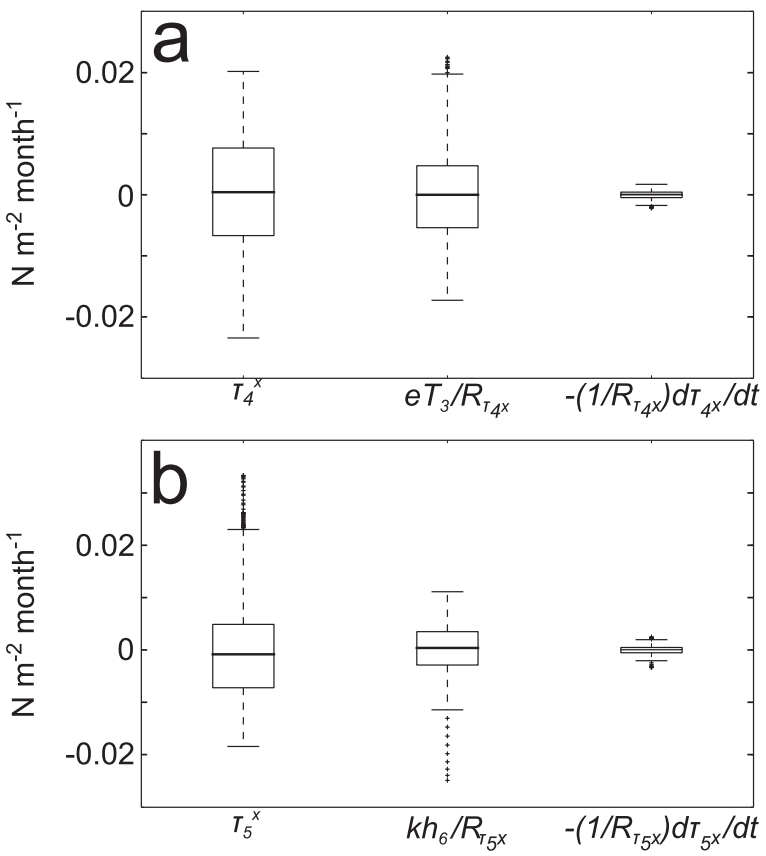

FIG. 10. The dominant balances of terms in the zonal wind stress anomaly Eqs. (4) and (5), rearranged to have the tendency terms on the right-hand side and the damping terms on the left. In each boxplot, the bold horizontal line represents the median value of the term (i.e., median value through time), the lower horizontal line of the box represents the 25 th percentile and the upper horizontal line represents the 75th percentile, the whiskers extend to the most extreme data points that are not considered outliers, and the crosses represent outlier data (i.e., outside the 99th percentile). (a) The terms in the Niño- $4^{*}\left(5^{\circ} \mathrm{S}-5^{\circ} \mathrm{N}, 150^{\circ} \mathrm{E}-160^{\circ} \mathrm{W}\right)$ zonal wind stress anomaly Eq. (4), where the parameter values are estimated by GLS regression. (b) The terms in the Niño-5 $\left(5^{\circ} \mathrm{S}-5^{\circ} \mathrm{N}, 120^{\circ}-\right.$ $140^{\circ} \mathrm{E}$ ) zonal wind stress anomaly Eq. (5), where the parameter values are estimated by GLS regression.

Syu and Neelin 2000; Mechoso et al. 2003). While such a time-dependent relationship has been found to improve the relationship between $\tau_{4}^{x}$ and $T_{3}$, we emphasize that this is not the case when a simple wind stress anomaly tendency term is included, as in the UO Eq. (4).

Finally, the original western Pacific oscillator equation for the Niño-4* zonal wind stress anomaly tendency, Eq. (17), is fit to the simulated tendency using GLS regression analysis, yielding a fitted curve that explains essentially none of the variance in $d \tau_{4}^{x} / d t$ estimated directly from ACCESS-OM $\left(\mathrm{rmse}=0.0012 \mathrm{~N} \mathrm{~m}^{-2}\right.$ month $160^{\circ} \mathrm{W}, \rho^{2}=1.0 \%$ ).

\section{d. Niño-5 zonal wind stress tendency equations}

There are only two versions of equations for $\tau_{5}^{x}$ among the UO, its underpinning models, and the original versions of these models: a prognostic version, as in the UO, and a diagnostic version that relates $\tau_{5}^{x}$ directly to $h_{6}$, as in the URO. 
First, the prognostic UO Eq. (5) for Niño-5 zonal wind stress anomaly is considered. The curve calculated using the W01 parameters explains essentially none of the variance in $d \tau_{5}^{x} / d t$. When the right-hand side of Eq. (5) is fit to the model $d \tau_{5}^{x} / d t$, the correlation coefficient between the fitted curve and $d \tau_{5}^{x} / d t$ is $3.6 \times 10^{-3}$ (Fig. 7d). Hence, as for Eq. (4), we argue that the derivative formulation here is inappropriate. Performing the same dominant balance analysis on a rearranged Eq. (5) as in the previous section for Eq. (20), we find that the tendency term $d \tau_{5}^{\chi} / d t$ is also uncorrelated with the model state and can be treated as noise. Unlike with Eq. (20), there is no coherent structure in the residual (i.e., $\tau_{5}^{x}-k h_{6} / R_{\tau_{5}^{x}}$ ), although this might be due to the fact that $\tau_{5}^{x}$ depends on $h_{6}$ through the parameterization of local SST anomalies, which are not represented in Eq. (5).

Second, the URO equation for the Niño-5 region zonal wind stress anomaly-which assumes a simple linear relationship between $\tau_{5}^{x}$ and $h_{6}$-is fit to the simulated $d \tau_{5}^{x} / d t$ and is not a considerable improvement over the fit of the UO equation: the linear relation explains only $3.5 \%$ of the variance in the model $\tau_{5}^{x}$.

\section{Does the fitted UO produce an oscillation?}

\section{a. The UO and its underpinning models}

To investigate whether the UO and its component models produce a realistic periodicity using the GLS fitted values, each of the systems of equations outlined in section 3 is solved numerically using the R statistical computing package deSolve (Soetaert et al. 2010). We find that in the absence of stochastic forcing the numerical solutions of the UO, UDO, URO, UWPO, and UARO do not oscillate. This result is not surprising given the poor fits of the equations for thermocline depth and zonal wind stress anomalies in each framework.

\section{b. The original conceptual model formulations}

We next investigate whether the original delayed, recharge, and western Pacific oscillators produce oscillations when solved using the GLS fitted values for the parameter values. Both the delayed and the recharge oscillators are found to produce oscillatory solutions, the period of which can be calculated analytically. Assuming solutions to the delayed oscillator of the form $\exp (i \sigma t)$, the dispersion relation is given by Mechoso et al. (2003) as

$$
\left(i \sigma-\frac{a e}{R_{\tau_{4}^{r}}}\right)=-\frac{b_{1} e}{R_{\tau_{4}^{r}}} \exp (-i \sigma \eta)
$$

yielding a period of 4.2 years using the values of the coefficients estimated by GLS regression. In the case of the recharge oscillator, the period can be calculated with the following expression by Mechoso et al. (2003):

$$
P=2 \pi\left\{\left(\frac{b_{2} k R_{h}}{R_{\tau_{5}^{x}}}\right)-\left[\left(\frac{a e-b_{1} e}{R_{\tau_{4}^{x}}}\right)^{2}+\left(\frac{c e}{R_{\tau_{4}^{x}}}\right)^{2}\right]\right\}^{-1 / 2} .
$$

Using the GLS estimated coefficients for the original recharge oscillator from Table 1, the period is 5.7 years. However, as for the UO and its underpinning models, the numerical solution of the original western Pacific oscillator using the GLS fitted values is not oscillatory.

Mechoso et al. (2003) investigate the realism of the original delayed and recharge oscillator conceptual models in diagnosing ENSO behaviors using two fitting methods: the first fit the conceptual models directly to CGCM data, and the second fit each of the individual balance relations that were employed in the derivation of the two conceptual models. Using fitting method 1, Mechoso et al. (2003) find that the simple models appear to reproduce a realistic ENSO period, but when the implied parameters estimated by this method are substituted into the individual balance relations, they result in erroneous estimates of amplitude and phase. Fitting method 2 results in more robust estimates for the parameter values, although it yields smaller ENSO periods for the delayed and recharge oscillators than estimated by the CGCM, which Mechoso et al. (2003) attribute to multiple scales of time dependence in the CGCM wind stress-SST anomaly relationship [although we note that such a time-dependent relationship is not adequately represented through the inclusion of a wind stress anomaly tendency term, as in the UO Eqs. (4) and (5)]. The same procedure outlined in Mechoso et al. (2003) is not carried out here; however, we can expect a similar result to theirs for the original delayed and recharge oscillators.

\section{Discussion and conclusions}

The unified oscillator (UO) is often cited as a concise description of ENSO that incorporates several existing paradigms of ENSO dynamics, such as the recharge oscillator, delayed oscillator, western Pacific oscillator, and advective-reflective oscillator. We have investigated this claim but find that the unified oscillator is no more effective at diagnosing ENSO behavior in the flux-forced Australian Community Climate and Earth-System Ocean Model (ACCESS-OM) than the delayed oscillator formulation that the unified oscillator incorporates. 
In the original formulation of the UO, W01 suggests suitable parameter values based on their capability to produce oscillations on interannual time scales in the coupled system of delay differential equations. When applied to the relevant equations, we find these values to be ineffective in capturing the associated ACCESS-OM tendencies of SST, ocean heat content, and zonal surface wind stress anomalies. As an alternative, and in order to assess the fidelity of the UO equations with respect to the simulated ENSO behavior in ACCESS-OM, we use generalized least squares regression analysis to find more appropriate parameter estimates. While the fitted curve of the UO SST anomaly equation replicates the model $d T_{3} / d t$ reasonably well, the remaining equations for thermocline depth and zonal wind stress anomalies capture essentially none of the variance in the ACCESSOM tendencies, and as a result, the estimated coefficient values substituted into the $\mathrm{UO}$ and its underpinning model equations fail to produce oscillatory solutions. This can be attributed to two key factors.

First, the inclusion of the derivative terms in the UO prognostic Eqs. (4) and (5) for zonal wind stress anomalies is inappropriate. An examination of the dominant balances in each of these equations indicates that simple steady-state equations, in which the zonal wind stresses change linearly with the predictors, are more appropriate than the derivative formulations. However, this does not imply that linear relationships between zonal wind stress anomalies and the corresponding predictors are sufficient.

Second, the averaging region of the thermocline depth anomaly defined in the UO is mismatched to the formulation. W01 argues that since observations show that the maximum interannual thermocline depth and sea level variations are in the off-equatorial region, the discharge and recharge of the equatorial Pacific is best modeled using Niño- $6^{*}\left(8^{\circ}-16^{\circ} \mathrm{N}, 150^{\circ}-170^{\circ} \mathrm{E}\right)$ thermocline depth anomalies. This conflicts with the arguments of Jin (1997a) and a study by Meinen and McPhaden (2000), who show that the discharge and recharge of equatorial heat content-that is, averaged in the western equatorial Pacific and the Niño- $3\left(5^{\circ} \mathrm{S}-5^{\circ} \mathrm{N}, 150^{\circ}-90^{\circ} \mathrm{W}\right)$ regions, respectively, rather than off-equatorial heat content-play an important role in the growth and decay of an ENSO event. Our results agree with these earlier studies; we find that when the heat content is averaged in the equatorial western Pacific, the variance explained in the ACCESS-OM thermocline depth anomaly tendency is considerably higher than when the thermocline depth anomaly is averaged in the off-equatorial western Pacific.

We find that the inclusion of the western Pacific oscillator feedback mechanism in the UO does not substantially improve the fit of this equation to the
ACCESS-OM $d T_{3} / d t$, as evidenced by comparing the SST anomaly equation from the UO and the delayed oscillator. Furthermore, both the original and the W01 versions of the western Pacific oscillator model capture very little of the variance in the SST, thermocline depth, and zonal wind stress anomaly tendencies that they describe. It is important to recognize that our results do not establish whether or not the dominant negative feedback described by the western Pacific oscillator is a physical mechanism-previous studies have found evidence for the western Pacific oscillator operating in nature, and particularly during large ENSO events (Boulanger and Menkes 2001; Boulanger et al. 2003). Rather, our results imply that the inclusion of the western Pacific oscillator in the UO in its present form is not necessary or sufficient for replicating the ENSO tendencies produced by the ACCESS-OM simulation.

A notable weakness of the UO theory is in combining mechanisms that are not necessarily independent. For example, the discharge of equatorial heat content in the recharge oscillator implicitly takes into account the Kelvin wave processes explained by the delayed oscillator negative feedback mechanism (Jin 1997a). That is, the time-integrated effect of eastward-propagating upwelling Kelvin waves initiated by the reflection of Rossby wave pairs at the western boundary of the Pacific (from the delayed oscillator) partly contribute to the ocean mass adjustment (from the recharge oscillator) that leaves the thermocline anomalously shallow following an El Niño event. While it may be true that the evolution of ENSO is the result of multiple negative feedback mechanisms acting in concert, the UO in its current form is unable to adequately incorporate and delineate the different mechanisms in operation.

With these factors in mind, and by comparing the UO equations with the corresponding equations from the original conceptual models it incorporates, we suggest a number of improvements to the UO:

1) define the averaging region for the thermocline depth anomaly in the western Pacific on, rather than off, equator, based on model sensitivity and/or the location of maximum interannual variability;

2) remove the tendency term in the Niño- $4^{*}\left(5^{\circ} \mathrm{S}-5^{\circ} \mathrm{N}\right.$, $150^{\circ} \mathrm{E}-160^{\circ} \mathrm{W}$ ) zonal wind stress equation;

3) remove the tendency term in the Niño- $5\left(5^{\circ} \mathrm{S}-5^{\circ} \mathrm{N}\right.$, $120^{\circ}-150^{\circ} \mathrm{E}$ ) zonal wind stress equation [the description of $\tau_{5}^{x}$ from Eq. (5) might be further improved via the inclusion of an explicit SST term, although evaluation of the most appropriate parameterization of this term requires further investigation]; and

4) include stochastic wind forcing in each of the zonal wind stress anomaly tendency equations to energize 
the fluctuations in the face of dissipation, as has been done for the recharge oscillator recently by Levine and Jin (2010).

Nevertheless, even with these modifications, it would be difficult for an improved unified model to significantly surpass the performance of the simple delayed oscillator equation in capturing the ENSO behavior of the ACCESS-OM simulation. For frequencies of 12 months or greater, and parameter values of $a e / R_{\tau_{4}^{x}}=0.16 \mathrm{month}^{-1}, b_{1} e / R_{\tau_{4}^{r}}=0.20 \mathrm{month}^{-1}$, and $\eta=5$, we find that the delayed oscillator Niño-3 SST anomaly tendency equation explains $94 \%$ of the variance in the corresponding tendency calculated directly from the ACCESS-OM data. Hence, we recommend the delayed oscillator model as a starting point for further research and improvement, which is summarized as follows:

$$
\begin{aligned}
& \frac{d T_{3}(t)}{d t}=\frac{a e}{R_{\tau_{4}^{x}}} \tau_{4}^{x}(t)-\frac{b_{1} e}{R_{\tau_{4}^{x}}} \tau_{4}^{x}(t-\eta), \\
& \text { for } \tau_{4}^{x}(t)=\frac{e}{R_{\tau_{4}^{x}}} T_{3}(t)+\alpha N(t) G(t), \\
& \frac{d N(t)}{d t}=-\omega N(t)+w(t),
\end{aligned}
$$

where we have introduced a multiplicative (state dependent) noise variable $N(t)$ representing red noise; $w(t)$ is white noise with a Gaussian distribution; $G=1+B T_{3}$; and $\alpha, \omega$, and $B$ are constants. These additions to the delayed oscillator are based on modifications to the original recharge oscillator by Levine and Jin (2010), who demonstrated that multiplicative noise influenced ENSO stability and asymmetry and confirmed previous findings that the low-frequency component of noise forcing is critical in the excitation of El Niño events (Vecchi et al. 2006; Gebbie et al. 2007; Zavala-Garay et al. 2008). We also note that multiplicative, rather than simply additive, noise is most appropriate, as it allows for the interdependence between high-frequency stochastic forcing events such as the Madden-Julian oscillation or westerly wind bursts, which are not independent of the background state of ENSO (Kessler and Kleeman 2000; Vecchi and Harrison 2000; Eisenman et al. 2005; Gebbie et al. 2007; Tziperman and $\mathrm{Yu}$ 2007). Additional improvement might be found in the delayed oscillator by including a nonlinearity in the atmospheric response to SST, as per Choi et al. (2013), an addition that resulted in a model better able to reproduce key ENSO asymmetries.

One limitation of the UO formulation, and of linear conceptual models in general, is the estimation of constant parameter values, when in reality ENSO is a nonlinear system with temporally evolving dynamics and spatial flavors (Yeh et al. 2014). Furthermore, these ENSO dynamics and spatial flavors are highly dependent on a mean state that is expected to warm into the future (e.g., Yeh et al. 2009; Kug et al. 2009; Wittenberg 2009; Collins et al. 2010; Vecchi and Wittenberg 2010; Santoso et al. 2013; Kim et al. 2014; Wittenberg et al. 2014; Capotondi et al. 2015). For example, the delay terms in Eqs. (2) and (3) depend on Kelvin and Rossby wave speeds and the location where the waves are generated, which are not necessarily stationary in time. The parameter values may also be influenced by the meridional breadth, duration, and location of wind forcing (Wittenberg 2002; Vecchi and Harrison 2003; Capotondi et al. 2006; Kim et al. 2008), which are not the same from one event to another.

Importantly, we are not arguing that the parameter values obtained from the application of generalized least squares regression analysis to the ACCESS-OM simulation are the "best" parameter values for any model. Indeed, it is expected that the application of the same analysis for a different model, or time period, will result in a different set of parameter values than those found here for the ACCESS-OM simulation. However, reanalysis products, such as SODA v2.2.4 and ERSST $\mathrm{v} 3 \mathrm{~b}$, are forced by similar atmospheric fluxes to those used to force the ACCESS-OM simulation (Griffies et al. 2012), resulting in similar reproductions of SST, thermocline depth, and wind stress anomalies, despite the fact that while reanalysis data are corrected to observations, the ACCESS-OM OGCM is not (Fig. 4). Therefore, replication of the analysis performed here on ACCESS-OM using reanalysis data is unlikely to produce a markedly different set of conclusions to those presented here.

Linear conceptual models have played, and will most likely continue to play, an important role in our understanding of ENSO behavior. Nevertheless, differences in ENSO flavors and variability in space and time, and the potential complexities associated with changes in ENSO behavior under climate change, predicate the need for a more complete consideration of the role and importance of nonlinearities in the climate system when making conclusions about modeled behaviors.

Acknowledgments. The authors wish to thank Simon Marsland and the ACCESS modeling team for providing the data. F.S.G. is supported by an Australian Postgraduate Award and a CSIRO Wealth from Oceans scholarship. This paper makes a contribution to addressing the goals of the Australian Research Council Centre of Excellence for Climate System Science. 


\section{APPENDIX}

\section{Derivation of the Unified Oscillator}

The equations that W01 used to derive the UO model are briefly introduced in this section.

As for the delayed oscillator model (Battisti and Hirst 1989), W01 assumes that the SST, vertical velocity, and zonal current velocity anomalies described in the Lamont model for SST anomaly tendencies (Zebiak and Cane 1987) are linearly related to zonal wind stress anomalies in the eastern equatorial Pacific, yielding

$$
\frac{d T_{3}}{d t}=R \tau_{4}^{x}+K_{E} h_{3},
$$

where $T_{3}$ is the Niño-3 $\left(5^{\circ} \mathrm{S}-5^{\circ} \mathrm{N}, 150-90^{\circ} \mathrm{W}\right)$ SST anomaly, $\tau_{4}^{x}$ is the Niño- $4^{*}\left(5^{\circ} \mathrm{S}-5^{\circ} \mathrm{N}, 150^{\circ} \mathrm{E}-160^{\circ} \mathrm{W}\right)$ zonal wind stress anomaly, $h_{3}$ is the Niño-3 thermocline depth anomaly, and $R$ and $K_{E}$ are constants. Battisti and Hirst (1989) used Eq. (A1) to directly derive the delayed oscillator by assuming that $\tau_{4}^{x}$ is proportional to the SST anomaly averaged in the eastern equatorial Pacific and that the zonal tilt in the equatorial thermocline depth is proportional to the zonal wind stress anomalies $\left(h_{3} \propto h_{W}+\tau_{4}^{x}\right)$. However, W01 argues that Eq. (A1) on its own overlooks the importance of the western equatorial Pacific zonal wind stress anomalies that are important in forcing an upwelling Kelvin wave that contributes to ENSO decay. Hence, to derive the UO, W01 considers Eq. (A1) and an equation describing the balance between the zonal tilt in the equatorial thermocline depth and zonal wind stresses (from the reduced gravity model):

$$
g^{\prime} \frac{\partial H}{\partial x}=\frac{\tau^{x}}{\rho_{0} H},
$$

where $g^{\prime}$ is the reduced gravity, $H$ is the mean thermocline depth, $\rho_{0}$ is a constant for the seawater density, and $\tau^{x}$ is the zonal wind stress. W01 integrates Eq. (A2) over the equatorial box from east to west and considers only the anomalous terms, obtaining

$$
h_{3}=h_{W}+\alpha \tau_{4}^{x}+\beta \tau_{5}^{x},
$$

where, as before, $\tau_{4}^{x}$ is the Niño- $4^{*}$ zonal wind stress anomaly, $\tau_{5}^{x}$ is the Niño-5 $\left(5^{\circ} \mathrm{S}-5^{\circ} \mathrm{N}, 120^{\circ}-140^{\circ} \mathrm{E}\right)$ zonal wind stress anomaly, $h_{3}$ is the Niño- 3 thermocline depth anomaly, $h_{W}$ is the western equatorial thermocline depth anomaly, and $\alpha$ and $\beta$ are constants. In the delayed oscillator, wave dynamics are responsible for modulating $5^{\circ} \mathrm{N}$ on ENSO time scales; hence, $h_{W}$ is assumed to be proportional to $-\tau_{4}^{x}(t-\eta)$. The third term on the right-hand side of Eq. (A3), $\beta \tau_{5}^{x}$, which does not appear in the delayed or recharge oscillators, describes the effect of Niño-5 zonal wind stress anomalies in forcing an upwelling Kelvin wave that acts to damp eastern equatorial Pacific SST anomalies (from the western Pacific oscillator; Weisberg and Wang 1997). This term is assumed to be proportional to $\tau_{5}^{x}(t-\delta)$, where $\delta$ represents the delay in the propagation of the Kelvin wave from west to east. Substitution of these terms into Eq. (A3) yields the following equation:

$$
h_{3}=\alpha \tau_{4}^{x}-\gamma \tau_{4}^{x}(t-\eta)+\beta \tau_{5}^{x}(t-\delta),
$$

which can then be substituted into Eq. (A1) to yield the UO equation for the Niño-3 SST anomaly tendency, namely,

$$
\frac{d T_{3}}{d t}=a \tau_{4}^{x}-b_{1} \tau_{4}^{x}(t-\eta)+b_{2} \tau_{5}^{x}(t-\delta),
$$

where

$$
a=R+\alpha K_{E}, \quad b_{1}=\gamma K_{E}, \quad b_{2}=\beta K_{E} .
$$

W01 further added a cubic damping term to Eq. (A5), $\varepsilon T_{3}^{3}$, to limit growth.

To derive the UO equation for the Niño- $6^{*}\left(8^{\circ}-16^{\circ} \mathrm{N}\right.$, $150^{\circ}-170^{\circ} \mathrm{E}$ ) thermocline depth anomaly tendency, Eq. (3), W01 starts from the vorticity equation describing the generation of off-equatorial Rossby waves:

$$
\frac{\partial h_{6}}{\partial t}-c_{r} \frac{\partial h_{6}}{\partial x}+R h=\nabla \times\left[\frac{\tau}{\rho_{0} f}\right],
$$

where $f$ is the Coriolis parameter, $c_{r}$ is the long Rossby wave speed, and $R$ is a damping term. W01 argues that it takes time (e.g., $\lambda$ months) for the off-equatorial Rossby waves to propagate west from the forcing region in the central-eastern equatorial Pacific and hence introduces a delay term into Eq. (A7) to obtain the UO Eq. (3), namely,

$$
\frac{d h_{6}}{d t}=-c \tau_{4}^{x}(t-\lambda)-R_{h_{6}},
$$

where the thermocline depth anomalies are averaged in the Niño-6* region and the zonal wind stress term is averaged in the Niño- $4 *$ region.

Finally, W01 derives the UO equations for the Niño-4* and Niño-5 zonal wind stress anomalies from a reduced-gravity atmospheric model, for example,

$$
\frac{\partial U}{\partial t}-B y V=-\frac{\partial P}{\partial x}-G U,
$$




$$
\begin{gathered}
B y U=-\frac{\partial P}{\partial y}, \\
\frac{\partial P}{\partial t}+c_{a}^{2}\left(\frac{\partial U}{\partial x}+\frac{\partial V}{\partial y}\right)=-Q-G P,
\end{gathered}
$$

where $U$ and $V$ are the zonal and meridional wind anomalies, $P$ is the atmospheric pressure anomaly, $c_{a}$ is the atmospheric Kelvin wave speed, and $G$ is an atmospheric damping term. This system is combined into one-third-order partial differential equation, and then, averaging from the eastern to the central equatorial Pacific and assuming that $Q$ is proportional to $T_{3}$, the UO Eqs. (4) and (5) are directly obtained:

$$
\begin{aligned}
& \frac{d \tau_{4}^{x}}{d t}=e T_{3}-R_{\tau_{4}} \tau_{4}^{x}, \\
& \frac{d \tau_{5}^{x}}{d t}=k h_{6}-R_{\tau_{5}} \tau_{5}^{x} .
\end{aligned}
$$

\section{REFERENCES}

Adcroft, A., and J.-M. Campin, 2004: Rescaled height coordinates for accurate representation of free-surface flows in ocean circulation models. Ocean Modell., 7, 269-284, doi:10.1016/ j.ocemod.2003.09.003.

Barnett, T. P., 1977: An attempt to verify some theories of El Niño. J. Phys. Oceanogr., 7, 633-647, doi:10.1175/ 1520-0485(1977)007<0633:AATVST > 2.0.CO;2.

Battisti, D. S., and A. C. Hirst, 1989: Interannual variability in a tropical atmosphere-ocean model: Influence of the basic state, ocean geometry and nonlinearity. J. Atmos. Sci., 46, 1687-1712, doi:10.1175/1520-0469(1989)046<1687: IVIATA $>2.0 . \mathrm{CO} ; 2$.

Bettio, L., 2007: On the character, dynamics, and predictability of ENSO in the observations and a coupled GCM. Ph.D. thesis, School of Earth Sciences, University of Melbourne, $314 \mathrm{pp}$.

Bi, D., and Coauthors, 2013a: ACCESS-OM: The ocean and sea-ice core of the ACCESS coupled model. Aust. Meteor. Oceanogr. J., 63, 213-232.

—_ , and Coauthors, 2013b: The ACCESS coupled model: Description, control climate and evaluation. Aust. Meteor. Oceanogr. J., 63, 41-64.

Bjerknes, J., 1969: Atmospheric teleconnections from the equatorial Pacific. Mon. Wea. Rev., 97, 163-172, doi:10.1175/ 1520-0493(1969)097<0163:ATFTEP > 2.3.CO;2.

Boulanger, J.-P., and C. Menkes, 1999: Long equatorial wave reflection in the Pacific Ocean from TOPEX/POSEIDON data during the 1992-1998 period. Climate Dyn., 15, 205-225, doi: $10.1007 / \mathrm{s} 003820050277$.

— thermodynamical model and the role of long equatorial wave reflection during the 1993-1998 TOPEX/POSEIDON period. Climate Dyn., 17, 175-186, doi:10.1007/PL00013734.

- S. Cravatte, and C. Menkes, 2003: Reflected and locally windforced interannual equatorial Kelvin waves in the western Pacific Ocean. J. Geophys. Res., 108, 3311, doi:10.1029/ 2002JC001760.

Brown, J. N., and A. V. Fedorov, 2010: Estimating the diapycnal transport contribution to warm water volume variations in the tropical Pacific Ocean. J. Climate, 23, 221-237, doi:10.1175/ 2009JCLI2347.1.

— , and Coauthors, 2013: Implications of CMIP3 model biases and uncertainties for climate projections in the western tropical Pacific. Climatic Change, 119, 147-161, doi:10.1007/ s10584-012-0603-5.

—, C. Langlais, and C. Maes, 2014: Zonal structure and variability of the western Pacific dynamic warm pool edge in CMIP5. Climate Dyn., 42, 3061-3076, doi:10.1007/s00382-013-1931-5.

Capotondi, A., A. T. Wittenberg, and S. Masina, 2006: Spatial and temporal structure of tropical Pacific interannual variability in 20th century coupled simulations. Ocean Modell., 15, 274-298, doi:10.1016/j.ocemod.2006.02.004.

_- , and Coauthors, 2015: Understanding ENSO diversity. Bull. Amer. Meteor. Soc., 96, 921-938, doi:10.1175/ BAMS-D-13-00117.1.

Carton, J. A., and B. S. Giese, 2008: A reanalysis of ocean climate using simple ocean data assimilation (SODA). Mon. Wea. Rev., 136, 2999-3017, doi:10.1175/2007MWR1978.1.

Choi, K., G. A. Vecchi, and A. T. Wittenberg, 2013: ENSO transition, duration and amplitude asymmetries: Role of the nonlinear wind stress coupling in a conceptual model. J. Climate, 26, 9462-9476, doi:10.1175/JCLI-D-13-00045.1.

Clarke, A. J., J. Wang, and S. Van Gorder, 2000: A simple warm-pool displacement ENSO model. J. Phys. Oceanogr., 30, 1679-1691, doi:10.1175/1520-0485(2000)030<1679:ASWPDE>2.0.CO;2.

_, S. Van Gorder, and G. Colantuono, 2007: Wind stress curl and ENSO discharge/recharge in the equatorial Pacific. J. Phys. Oceanogr., 37, 1077-1091, doi:10.1175/JPO3035.1.

Collins, M., and Coauthors, 2010: The impact of global warming on the tropical Pacific Ocean and El Niño. Nat. Geosci., 3, 391367, doi:10.1038/ngeo868.

Delworth, T. L., and Coauthors, 2006: GFDL's CM2 global coupled climate models. Part I: Formulation and simulation characteristics. J. Climate, 19, 643-674, doi:10.1175/JCLI3629.1.

__ , and Coauthors, 2012: Simulated climate and climate change in the GFDL CM2.5 high-resolution coupled climate model. J. Climate, 25, 2755-2781, doi:10.1175/ JCLI-D-11-00316.1.

Dong, L., T. J. Vogelsang, and S. J. Colucci, 2008: Interdecadal trend and ENSO-related interannual variability in Southern Hemisphere blocking. J. Climate, 21, 3068-3077, doi:10.1175/ 2007JCLI1593.1.

Duan, W., Y. Yu, and P. Zhao, 2013: Behaviors of nonlinearities modulating the El Niño events induced by optimal precursory disturbances. Climate Dyn., 40, 1399-1413, doi:10.1007/ s00382-012-1557-z.

Dunne, J. P., and Coauthors, 2012: GFDL's ESM2 global coupled climate-carbon earth system models. Part I: Physical formulation and baseline simulation characteristics. J. Climate, 25, 6646-6665, doi:10.1175/JCLI-D-11-00560.1.

Eisenman, I., L. Yu, and E. Tziperman, 2005: Westerly wind bursts: ENSO's tail rather than the dog? J. Climate, 18, 5224-5238, doi:10.1175/JCLI3588.1.

Gebbie, G., I. Eisenman, A. T. Wittenberg, and E. Tziperman, 2007: Modulation of westerly wind bursts by sea surface temperature: A semistochastic feedback for ENSO. J. Atmos. Sci., 64, 3281-3295, doi:10.1175/JAS4029.1.

Gnanadesikan, A., and Coauthors, 2006: GFDL's CM2.1 global coupled climate models. Part II: The baseline ocean simulation. J. Climate, 19, 675-697, doi:10.1175/JCLI3630.1.

Graham, F. S., J. N. Brown, C. Langlais, S. J. Marsland, A. T. Wittenberg, and N. J. Holbrook, 2014: Effectiveness of the 
Bjerknes stability index in representing ocean dynamics. Climate Dyn., 43, 2399-2414, doi:10.1007/s00382-014-2062-3.

Griffies, S. M., and Coauthors, 2011: The GFDL CM3 coupled climate model: Characteristics of the ocean and sea ice simulations. J. Climate, 24, 3520-3544, doi:10.1175/ 2011JCLI3964.1.

—, M. Winton, B. L. Samuels, G. Danabasoglu, S. G. Yeager, S. J. Marsland, H. Drange, and M. Bentsen, 2012: Datasets and protocol for the CLIVAR WGOMD Coordinated Ocean-Sea Ice Reference Experiments (COREs). WCRP Rep. No. 21/ 2012, pp. 21.

Guilyardi, E., P. Delecluse, S. Gualdi, and A. Navarra, 2003: Mechanisms for ENSO phase change in a coupled GCM. J. Climate, 16, 1141-1158, doi:10.1175/1520-0442(2003)16<1141: MFEPCI $>2.0 . \mathrm{CO} ; 2$.

—, A. Wittenberg, A. Fedoro, M. Collins, C. Wang, A. Capotondi, G. J. van Oldenborgh, and T. Stockdale, 2009: Understanding El Niño in ocean-atmosphere general circulation models. Bull. Amer. Meteor. Soc., 90, 325-340, doi:10.1175/2008BAMS2387.1.

Ham, Y.-G., and J.-S. Kug, 2012: How well do current climate models simulate two types of El Niño? Climate Dyn., 39, 383-398, doi:10.1007/s00382-011-1157-3.

Hasegawa, T., and K. Hanawa, 2003: Heat content variability related to ENSO events in the Pacific. J. Phys. Oceanogr., 33, 407-421, doi:10.1175/1520-0485(2003)033<0407:HCVRTE>2.0.CO;2.

Hastie, T., R. Tibshirani, and J. Friedman, 2001: The Elements of Statistical Learning. Springer, 533 pp.

Jia, L., and Coauthors, 2015: Improved seasonal prediction of temperature and precipitation over land in a high-resolution GFDL climate model. J. Climate, 28, 2044-2062, doi:10.1175/ JCLI-D-14-00112.1.

Jin, F.-F., 1997a: An equatorial ocean recharge paradigm for ENSO. Part I: Conceptual model. J. Atmos. Sci., 54, 811-829, doi:10.1175/1520-0469(1997)054<0811:AEORPF >2.0.CO;2.

_ 1997b: An equatorial ocean recharge paradigm for ENSO. Part II: A stripped-down coupled model. J. Atmos. Sci., 54, 830-847, doi:10.1175/1520-0469(1997)054<0830:AEORPF>2.0.CO;2.

Kessler, W. S., 1990: Observations of long Rossby waves in the northern tropical Pacific. J. Geophys. Res., 95, 5183-5219, doi:10.1029/JC095iC04p05183.

_ 1991: Can reflected extra-equatorial Rossby waves drive ENSO? J. Phys. Oceanogr., 21, 444-452, doi:10.1175/ 1520-0485(1991)021<0444:CREERW >2.0.CO;2.

_- , and R. Kleeman, 2000: Rectification of the MaddenJulian oscillation into the ENSO cycle. J. Climate, 13, 3560-3575, doi:10.1175/1520-0442(2000)013<3560: ROTMJO $>2.0 . \mathrm{CO} ; 2$.

Kim, D., J.-S. Kug, I.-S. Kang, F.-F. Jin, and A. T. Wittenberg, 2008: Tropical Pacific impacts of convective momentum transport in the SNU coupled GCM. Climate Dyn., 31, 213-226, doi:10.1007/s00382-007-0348-4.

Kim, S. T., W. Cai, F.-F. Jin, A. Santoso, L. Wu, E. Guilyardi, and S.-I. An, 2014: Response of El Niño sea surface temperature variability to greenhouse warming. Nat. Climate Change, $\mathbf{4}$, 786-790, doi:10.1038/nclimate2326.

Kug, J.-S., F.-F. Jin, and S.-I. An, 2009: Two types of El Niño events: Cold tongue $\mathrm{El}$ Niño and warm pool El Niño. J. Climate, 22, 1499-1515, doi:10.1175/2008JCLI2624.1.

_ J. Choi, S.-I. An, F.-F. Jin, and A. T. Wittenberg, 2010: Warm pool and cold tongue El Niño events as simulated by the GFDL 2.1 coupled GCM. J. Climate, 23, 1226-1239, doi:10.1175/2009JCLI3293.1.
— Y.-Y. Ham, J.-Y. Lee, and F.-F. Jin, 2012: Improved simulation of two types of El Niño in CMIP5 models. Environ. Res. Lett., 7, 034002, doi:10.1088/1748-9326/7/3/034002.

Large, W. G., and S. G. Yeager, 2009: The global climatology of an interannually varying air-sea flux data set. Climate Dyn., 33, 341-364, doi:10.1007/s00382-008-0441-3.

Levine, A. F. Z., and F.-F. Jin, 2010: Noise-induced instability in the ENSO recharge oscillator. J. Atmos. Sci., 67, 529-542, doi:10.1175/2009JAS3213.1.

Li, B., and A. J. Clarke, 1994: An examination of some ENSO mechanisms using interannual sea level at the eastern and western equatorial boundaries and the zonally averaged equatorial wind. J. Phys. Oceanogr., 24, 681-690, doi:10.1175/ 1520-0485(1994)024<0681:AEOSEM > 2.0.CO;2.

Lima, C. H. R., U. Lall, T. Jebara, and A. G. Barnston, 2009: Statistical prediction of ENSO from subsurface sea temperature using a nonlinear dimensionality reduction. J. Climate, 22, 4501-4519, doi:10.1175/2009JCLI2524.1.

Mantua, N. J., and D. S. Battisti, 1994: Evidence of the delayed oscillator mechanism for ENSO: The "observed" oceanic Kelvin mode in the far western Pacific. J. Phys. Oceanogr., 24, 691-699, doi:10.1175/1520-0485(1994)024<0691:EFTDOM>2.0.CO;2.

McPhaden, M. J., 2003: Tropical Pacific Ocean heat content variations and ENSO persistence barriers. Geophys. Res. Lett., 30, 1480, doi:10.1029/2003GL016872.

- 2004: Evolution of the 2002/03 El Niño. Bull. Amer. Meteor. Soc., 85, 677-695, doi:10.1175/BAMS-85-5-677.

2012: A 21st century shift in the relationship between ENSO SST and warm water volume anomalies. Geophys. Res. Lett., 39, L09706, doi:10.1029/2012GL051826.

- and X. Yu, 1999: Equatorial waves and the 1997-98 El Niño. Geophys. Res. Lett., 26, 2961-2964, doi:10.1029/1999GL004901.

Mechoso, C. R., J. D. Neelin, and J.-Y. Yu, 2003: Testing simple models of ENSO. J. Atmos. Sci., 60, 305-318, doi:10.1175/ 1520-0469(2003)060<0305:TSMOE $>2.0 . \mathrm{CO} ; 2$.

Meinen, C. S., and M. J. McPhaden, 2000: Observations of warm water volume changes in the equatorial Pacific and their relationship to El Niño and La Niña. J. Climate, 13, 3551-3559, doi:10.1175/1520-0442(2000)013<3551:OOWWVC >2.0.CO;2.

—, and —, 2001: Interannual variability in warm water volume transport in the equatorial Pacific during 199399. J. Phys. Oceanogr., 31, 1324-1345, doi:10.1175/ 1520-0485(2001)031<1324:IVIWWV>2.0.CO;2.

Meyers, G., 1979: On the annual Rossby wave in the tropical North Pacific Ocean. J. Phys. Oceanogr., 9, 663-674, doi:10.1175/ 1520-0485(1979)009<0663:OTARWI >2.0.CO;2.

Neelin, J. D., F.-F. Jin, and H.-H. Syu, 2000: Variations in ENSO phase-locking. J. Climate, 13, 2570-2590, doi:10.1175/ 1520-0442(2000)013<2570:VIEPL>2.0.CO;2.

Picaut, J., M. Ioualalen, C. Menkes, T. Delcroix, and M. J. McPhaden, 1996: Mechanism of the zonal displacements of the Pacific warm pool: Implications for ENSO. Science, 274, 1486-1489, doi:10.1126/science.274.5292.1486.

_ , F. Masia, and Y. du Penhoat, 1997: An advective-reflective conceptual model for the oscillatory nature of the ENSO. Science, 277, 663-666, doi:10.1126/science.277.5326.663.

Power, S., M. Haylock, R. A. Colman, and X. Wang, 2006: The predictability of interdecadal changes in ENSO activity and ENSO teleconnections. J. Climate, 19, 4755-4771, doi:10.1175/ JCLI3868.1.

R Development Core Team, 2008: R: A Language and Environment for Statistical Computing. R Foundation for Statistical Computing, 409 pp. 
Santoso, A., S. McGregor, F.-F. Jin, W. Cai, M. H. England, S.-I. An, M. J. McPhaden, and E. Guilyardi, 2013: Late-twentieth-century emergence of the El Niño propagation asymmetry and future projections. Nature, 504, 126-130, doi:10.1038/nature12683.

Schneider, E. K., Z. X. Zhu, B. S. Giese, B. H. Huang, B. P. Kirtman, J. Shukla, and J. A. Carton, 1997: Annual cycle and ENSO in a coupled ocean-atmosphere general circulation model. Mon. Wea. Rev., 125, 680-702, doi:10.1175/1520-0493(1997)125<0680: ACAEIA $>2.0 . \mathrm{CO} ; 2$.

Schopf, P. S., and M. J. Suarez, 1988: Vacillations in a coupled ocean-atmosphere model. J. Atmos. Sci., 45, 549-566, doi:10.1175/1520-0469(1988)045<0549:VIACOM >2.0.CO;2.

Shu, L., and A. J. Clarke, 2002: Using an ocean model to examine ENSO dynamics. J. Phys. Oceanogr., 32, 903-923, doi:10.1175/ 1520-0485(2002)032<0903:UAOMTE >2.0.CO;2.

Singh, A., and T. Delcroix, 2013: Eastern and central Pacific ENSO and their relationships to the recharge/discharge oscillator paradigm. Deep-Sea Res. I, 82, 32-43, doi:10.1016/ j.dsr.2013.08.002.

Smith, N. R., 1995: An improved system for tropical ocean subsurface temperature analyses. J. Atmos. Oceanic Technol., 12, 850-870, doi:10.1175/1520-0426(1995)012<0850: AISFTO $>2.0 . \mathrm{CO} ; 2$.

Soetaert, K., T. Petzoldt, and R. W. Setzer, 2010: Solving differential equations in r: Package deSolve. J. Stat. Software, 33 (9), 1-25. [Available online at http://www.jstatsoft.org/v33/i09.]

Suarez, M. J., and P. S. Schopf, 1988: A delayed action oscillator for ENSO. J. Atmos. Sci., 45, 3283-3287, doi:10.1175/ 1520-0469(1988)045<3283:ADAOFE > 2.0.CO;2.

Syu, H.-H., and J. D. Neelin, 2000: ENSO in a hybrid coupled model. Part I: Sensitivity to physical parameterizations. Climate Dyn., 16, 19-34, doi:10.1007/PL00007920.

Tziperman, E., and L. Yu, 2007: Quantifying the dependence of westerly wind bursts on the large-scale tropical Pacific SST. J. Climate, 20, 2760-2768, doi:10.1175/JCLI4138a.1.

Vannière, B., E. Guilyardi, G. Madec, F. J. Doblas-Reyes, and S. Woolnough, 2013: Using seasonal hindcasts to understand the origin of the equatorial cold tongue bias in CGCMs and its impact on ENSO. Climate Dyn., 40, 963-981, doi:10.1007/ s00382-012-1429-6.

Vecchi, G. A., and D. E. Harrison, 2000: Tropical Pacific sea surface temperature anomalies, El Niño, and equatorial westerly wind events. J. Climate, 13, 1814-1830, doi:10.1175/ 1520-0442(2000)013<1814:TPSSTA > 2.0.CO;2.

- , and — , 2003: On the termination of the 2002-03 El Niño event. Geophys. Res. Lett., 30, 1964, doi:10.1029/ 2003 GL017564.

, and A. T. Wittenberg, 2010: El Niño and our future climate: Where do we stand? Wiley Interdiscip. Rev.: Climate Change, 1, 260-270, doi:10.1002/wcc.3.
,-- , and A. Rosati, 2006: Reassessing the role of stochastic forcing in the 1997-1998 El Niño. Geophys. Res. Lett., 33, L01706, doi:10.1029/2005GL024738.

_ tropical cyclone activity. J. Climate, 27, 7994-8016, doi:10.1175/JCLI-D-14-00158.1.

von Storch, H., and F. W. Zwiers, 1999: Statistical Analysis in Climate Research. Cambridge University Press, 484 pp.

Wang, C., 2001: A unified oscillator model for the El NiñoSouthern Oscillation. J. Climate, 14, 98-115, doi:10.1175/ 1520-0442(2001)014<0098:AUOMFT>2.0.CO;2.

_ view. Earth's Climate: The Ocean-Atmosphere Interaction, Geophys. Monogr., Vol. 147, Amer. Geophys. Union, 21-48.

Weisberg, R. H., and C. Wang, 1997: A western Pacific oscillator paradigm for the El Niño-Southern Oscillation. Geophys. Res. Lett., 24, 779-782, doi:10.1029/97GL00689.

Wittenberg, A. T., 2002: ENSO response to altered climates. Ph.D. thesis, Princeton University, $475 \mathrm{pp}$. [Available online at http://gfdl.noaa.gov/ atw/research/thesis/.]

- 2004: Extended wind stress analyses for ENSO. J. Climate, 17, 2526-2540, doi:10.1175/1520-0442(2004)017<2526: EWSAFE $>2.0 . \mathrm{CO} ; 2$.

_ 2009: Are historical records sufficient to constrain ENSO simulations? Geophys. Res. Lett., 36, L12702, doi:10.1029/ 2009GL038710.

— A. Rosati, N.-C. Lau, and J. J. Ploshay, 2006: GFDL's CM2 global coupled climate models. Part III: Tropical Pacific climate and ENSO. J. Climate, 19, 698-722, doi:10.1175/ JCLI3631.1.

,-- T T. L. Delworth, G. A. Vecchi, and F. Zeng, 2014: ENSO modulation: Is it decadally predictable? J. Climate, 27, 2667-2681, doi:10.1175/JCLI-D-13-00577.1.

Yeh, S.-W., J.-S. Kug, B. Dewitte, M.-H. Kwon, B. P. Kirtman, and F.-F. Jin, 2009: El Niño in a changing climate. Nature, 461, 511-514, doi:10.1038/nature08316.

,-- , and S.-I. An, 2014: Recent progress on two types of El Niño: Observations, dynamics, and future changes. Asia-Pac. J. Atmos. Sci., 50, 69-81, doi:10.1007/s13143-014-0028-3.

Yu, J.-Y., and S. T. Kim, 2010: Identification of central-Pacific and eastern-Pacific types of ENSO in CMIP3 models. Geophys. Res. Lett., 37, L15705, doi:10.1029/2010GL044082.

Zavala-Garay, J., C. Zhang, A. M. Moore, A. T. Wittenberg, M. J. Harrison, A. Rosati, J. Vialard, and R. Kleeman, 2008: Sensitivity of hybrid ENSO models to unresolved atmospheric variability. J. Climate, 21, 3704-3721, doi:10.1175/ 2007JCLI1188.1.

Zebiak, S. E., and M. Cane, 1987: A model El Niño-Southern Oscillation. Mon. Wea. Rev., 115, 2262, doi:10.1175/ 1520-0493(1987)115<2262:AMENO>2.0.CO;2. 